Submitted for Publication to the

International Journal of Chemical Kinetics

July 8, 2004

\title{
Temperature-Dependent Feature Sensitivity Analysis for Combustion Modeling
}

\author{
Zhenwei Zhao, Juan Li, Andrei Kazakov, and Frederick L. Dryer \\ Department of Mechanical and Aerospace Engineering \\ Princeton University \\ Princeton, NJ 08544-5263 \\ USA
}

Corresponding Author:

Frederick L. Dryer

Phone: (609)-258-5206

Fax: (609)-258-1939

E-Mail: fldryer@princeton.edu 


\title{
Temperature-Dependent Feature Sensitivity Analysis for Combustion Modeling
}

\author{
Zhenwei Zhao, Juan Li, Andrei Kazakov, and Frederick L. Dryer \\ Department of Mechanical and Aerospace Engineering \\ Princeton University, Princeton, NJ 08544
}

\begin{abstract}
Sensitivity analysis is one of the most widely used tools in kinetic modeling. Typically, it is performed by perturbing the $A$-factors of the individual reaction rate coefficients and monitoring the effect of these perturbations on the observables of interest. However, the sensitivity coefficients obtained in this manner do not contain any information on possible temperature dependent effects. Yet, in many combustion processes, especially in premixed flames, the system undergoes substantial temperature changes, and the relative importance of individual reaction rates may vary significantly within the flame. An extension of conventional sensitivity analysis developed in the present work provides the means of identifying the temperatures at which individual reaction rate coefficients are most important as a function of input parameters and specific experimental conditions. The obtained information is demonstrated to be of critical relevance in optimizing complex reaction schemes against multiple experimental targets. Applications of the presented approach are not limited to sensitivities with respect to reaction rate coefficients; the method can be used for any temperaturedependent property of interest (such as binary diffusion coefficients). This application is also demonstrated in this paper.
\end{abstract}




\section{Introduction}

Modeling of combustion phenomena requires knowledge of reaction rates, diffusion coefficients, and other physical/chemical properties of the reactants as input parameters, and produces the observables (such as species concentration and temperature profiles, laminar flame speed) as the output, with the input and the output connected by dynamic equations. Application of sensitivity analysis, a useful and efficient approach to examine the relationship of the underlying input and output, has been adopted in kinetic modeling sometime ago (e.g., [1,2]). Since sensitivity analysis methods were introduced to combustion research (e.g., [3-5]), they have widely used either to aid in qualitatively understanding the observed kinetic behavior or to assist in improving or optimizing kinetic models. Sensitivity analyses are usually performed on the reaction rates, specifically the $A$-factors of the corresponding rate coefficients, by perturbing them with a small constant, thus essentially perturbing the specific rate constant over the entire temperature range of the calculation (Fig. 1). However, in many combustion processes, especially in flames, the system transformation inherently occurs over a very wide range of temperature. Given the fact that reaction rates generally exhibit widely differing and nonlinear dependence on temperature, the relative sensitivities of the reactions are also expected to vary with temperature. Sensitivity methods that vary only $A$-factors cannot provide information on temperature dependence of the sensitivity spectrum.

Free-radical diffusion rates can be as critical as elementary reaction kinetics in accurately predicting a combustion process, and the main model input parameters (binary diffusion coefficients) are also temperature-dependent. Although the importance of species diffusion in flame kinetics has long been recognized, sensitivity analysis with respect to diffusion coefficients was not commonly performed until very recently [6]. Mishra et al. [6] applied sensitivity analysis to a burner-stabilized flame to qualitatively describe the influence of diffusion coefficients on the predicted flame structure. More recent efforts by Yang et al. [7] and Middha et al. [8] have focused on the effects of binary diffusion coefficients on laminar flame speed. In these works, sensitivity analysis was performed in a similar manner as for the reaction rates, i.e. no temperature-dependent information was obtained. 
In this work, temperature-dependent sensitivity coefficients with respect to elementary reaction rate coefficients and binary diffusion coefficients for premixed flames were obtained by applying a small temperature-dependent perturbation to the property of interest. The perturbation was taken to be a Gaussian function of temperature, and the center of the Gaussian profile was varied with the assigned temperature mean. By gradually moving the center of this Gaussian window, new, temperature-dependent sensitivity coefficients are obtained. A similar idea has recently been suggested by Rumminger et al. [9]. Rumminger et al. used a rectangular-shaped perturbation (which they called a "band") in premixed flame simulations to identify the temperature ranges where the flame suppression by inhibitors is expected to be most effective. A series of tests was performed for atmospheric $\mathrm{CH}_{4} /$ air laminar premixed free flames, and, amongst the particular tests, Rumminger et al. [9] reported temperaturedependent responses of predicted laminar flame speed to the perturbations applied to two important reactions,

$\mathrm{H}+\mathrm{O}_{2}=\mathrm{OH}+\mathrm{O}$

and

$$
\mathrm{CO}+\mathrm{OH}=\mathrm{CO}_{2}+\mathrm{H} \text {. }
$$

Here, we propose a more rigorous methodology and apply it in a systematic manner to a number of cases relevant to detailed reaction model development, with broader implications with respect to combustion modeling in general.

The sensitivity parameters for several elementary reactions, such as $\mathrm{H}+\mathrm{O}_{2}=\mathrm{OH}$ $+\mathrm{O},(\mathrm{R} 1), \mathrm{CO}+\mathrm{OH}=\mathrm{CO}_{2}+\mathrm{H},(\mathrm{R} 2), \mathrm{HCO}+\mathrm{M}=\mathrm{CO}+\mathrm{H}+\mathrm{M},(\mathrm{R} 3), \mathrm{HCO}+\mathrm{O}_{2}=\mathrm{CO}$ $+\mathrm{HO}_{2}(\mathrm{R} 4)$, and $\mathrm{H}+\mathrm{O}_{2}(+\mathrm{M})=\mathrm{HO}_{2}(+\mathrm{M})(\mathrm{R} 5)$ were obtained for $\mathrm{H}_{2}, \mathrm{H}_{2} / \mathrm{CO}, \mathrm{CH}_{3} \mathrm{OH}$, and $\mathrm{C}_{3} \mathrm{H}_{8}$ kinetic flame models. The temperature-dependent sensitivity of binary diffusion coefficients of $\mathrm{H}$-atom with $\mathrm{He}$ and $\mathrm{H}_{2} \mathrm{O}$ were also determined for selected conditions. The obtained results were analyzed to identify the physical/chemical mechanisms responsible for the observed behavior. The practical examples through which we demonstrate the utility of the present methodology for development of comprehensive kinetic models are discussed in detail below. 


\section{Methodology and Implementation}

To develop a more general formulation, we consider a dynamic system which yields an observable $F(\mathbf{x}, \alpha)$ given a vector of variables $\mathbf{x}$ and vector of parameters $\alpha$. Elementary sensitivity gradient (coefficient) $S_{i}$ with respect to the parameter $\alpha_{i}$ for the observable $F$ is defined as

$$
S_{i}=\frac{\partial F}{\partial \alpha_{i}}
$$

In combustion modeling, it is more common to use logarithmic sensitivity gradients (or normalized sensitivity coefficients),

$$
s_{i}=\frac{\partial \log F}{\partial \log \alpha_{i}}=\frac{\alpha_{i}}{F} \frac{\partial F}{\partial \alpha_{i}}
$$

to follow relative (rather than absolute) changes in problem input parameters and observables. In practice, the system parameter $\alpha_{i}$ is usually written in the form

$$
\alpha_{i}=\alpha_{i}^{0}\left(1+p_{i}\right)
$$

where $\alpha_{i}^{0}$ is the baseline value of the parameter and $p_{i}$ is the perturbation. Although $\alpha_{i}$ itself may be a function of system variables $\mathbf{x}$, the perturbation $p_{i}$ is usually treated as an independent variable, i.e., it is applied in a uniform manner over the entire range of possible variation in $\alpha_{i}$. In such a case, Eq. (2) is presented as

$$
s_{i}=\left.\frac{1}{F} \frac{\partial F}{\partial p_{i}}\right|_{p_{i} \rightarrow 0} .
$$

Next, we consider the situation when the system parameter $\alpha_{i}$ is, in fact, a function of one of the system variables, $x_{j}$. In this case, the sensitivity coefficient given by Eq. (4) is still pertinent in providing, for example, relative importance of $\alpha_{i}$ in comparison with other parameters in the system. However, it may also be of interest to know specific conditions (range of $x_{j}$ ) where $F$ is most sensitive to variation in $\alpha_{i}$. This information is unavailable due to the global nature of the perturbation $p_{i}$ used to determine $s_{i}$ in Eq. (4). Use of local (with respect to $x_{j}$ ) perturbation of $\alpha_{i}$ appears to be the logical step to address this issue. Here, we propose a perturbation that is Gaussianshaped with respect to $x_{j}$, 


$$
p_{i}=\frac{x_{j}^{\mathrm{p}}}{\sqrt{2 \pi} \sigma} \exp \left[-\frac{\left(x_{j}-x_{j}^{\mathrm{c}}\right)^{2}}{2 \sigma^{2}}\right],
$$

where $x_{j}^{\mathrm{c}}$ is the center of the perturbation, $\sigma$ the width of the perturbation, and $x_{j}^{\mathrm{p}}$ the magnitude of the perturbation. Using the perturbation defined by Eq. (5), we introduce a new sensitivity coefficient,

$$
\xi_{i}\left(x_{j}^{\mathrm{c}}\right)=\left.\frac{1}{F} \frac{\partial F}{\partial x_{j}^{\mathrm{p}}}\right|_{x_{j}^{p} \rightarrow 0, \sigma \rightarrow 0},
$$

which is a function of the center of perturbation, $x_{j}^{\mathrm{c}}$. We note that Eq. (6) corresponds to the limit when the functional form of the Gaussian perturbation is reduced to a Dirac delta function. However, we retain the definition of perturbation via Eq. (5) since it will be used in actual numerical implementation of the proposed approach.

The physical meaning of the new sensitivity analysis is further illustrated in Fig. 1. The global perturbation used to define the sensitivity coefficient $s_{i}$, Eq. (4), is independent of $x_{j}$ and shown with a straight horizontal line. The local perturbations shown with a series of narrow Gaussian peaks, on the other hand, are confined to the regions around the corresponding centers of the perturbations. By moving the Gaussian probe along the $x_{j}$ axis and monitoring the response of $F$ to this perturbation, $\xi_{i}$ is defined as a function of the center of the probe. Having this information, one can quantitatively identify the range(s) of $x_{j}$ where the impact of variation in $\alpha_{i}$ would be the greatest. In practical applications, system parameters $\alpha_{i}$ always have uncertainties that may also vary with $x_{j}$. The sensitivity coefficient $\xi_{i}$ can therefore be used as a guidance tool to determine conditions at which $\alpha_{i}$ should be defined with high precision in order to yield accurate predictions of $F$.

\section{Practical Implementation: Laminar Flame Speed}

For the remainder of the paper, we demonstrate this new sensitivity analysis approach using a laminar premixed free flame system as an example. The main observable for this system is laminar flame speed $s_{\mathrm{L}}$, a fundamental property often used to partially validate detailed reaction mechanisms. Thus, $s_{\mathrm{L}}$ is used as marker of the 
system response to the parameter change, i.e., as an observable $F$ in Eqs (4) and (6). The primary parameters describing the system are the rate coefficients of chemical reactions composing the detailed reaction model. The rate coefficients are strongly-nonlinear functions of one of the system variables, the temperature $T$. Furthermore, the rate coefficients are rarely defined with sufficient accuracy over the entire range of temperatures encountered in flames. More commonly, rate coefficients are obtained by correlation of experimental measurements over a limited temperature range and then extrapolated outside this range using various analytical expressions. Accuracies of the original correlation as well as the extrapolation are difficult to assess and usually remain as open questions. On the other hand, flames represent systems where the temperature variations during the combustion process are very large as compared to other systems normally used to study chemical kinetics (such as shock tubes and flow reactors). Therefore, the use of sensitivity coefficients based on local (with respect to the temperature) perturbation, Eq. (5), offers an opportunity to identify the "temperature windows of importance" for specific reactions controlling the flame propagation. Because the sensitivity coefficients (6) will be considered exclusively in terms of their temperature dependence in all of the following examples, we redefine parameter notations in the Gaussian perturbation (5),

$$
p_{i}=\frac{T_{\mathrm{p}}}{\sqrt{2 \pi} T_{\sigma}} \exp \left[-\frac{\left(T-T_{c}\right)^{2}}{2 T_{\sigma}^{2}}\right],
$$

to make their meaning more clear, i.e., $T_{\mathrm{c}}$ is the center, $T_{\sigma}$ the width, and $T_{\mathrm{p}}$ the magnitude of the perturbation. For the same reason, the sensitivity coefficient will be referred to as simply $\xi(T)$, without a subscript.

A modified version of PREMIX package $[10,11]$ was used in all flame calculations. As in the original PREMIX formulation, the sensitivities reported here are computed for the net reaction rates, i.e., equilibrium constants for reversible reactions were unaltered when the perturbation was applied. An algorithm based on the numerical Jacobian implemented in PREMIX was adopted to compute the sensitivity coefficients. Davis et al. [12] have recently argued that direct brute-force method yields more accurate results as compared to the PREMIX's numerical Jacobian method. We also performed several tests with brute-force calculations and reached similar conclusions; however, the 
accuracy of the numerical Jacobian method was found to be acceptable for the purposes of the present work and offers substantial savings in computational time.

\section{Results and Discussion}

Simulations were carried out for hydrogen, carbon monoxide, methanol, and propane laminar premixed (free) flames. Different reaction models were chosen for different fuels based primarily on the their ability to accurately predict the flame speeds over the entire equivalence ratio range. For hydrogen flames, we used the updated hydrogen mechanism of Li et al. [13]. The mechanism of Mueller et al. [14] updated with the hydrogen sub-mechanism of $\mathrm{Li}$ et al. [13] was adopted for $\mathrm{CO} / \mathrm{H}_{2}$ flame calculations. The sensitivity analysis for methanol flames was performed with kinetic model of Held et al. [15]. Finally, the optimized $C_{1}-C_{3}$ mechanism of Qin et al. [16] was utilized for propane flames.

\section{Sensitivity Analysis for Hydrogen Combustion Mechanism}

The "conventional" sensitivity spectrum based on Eq. (4) for laminar flame speed of $\mathrm{H}_{2}$ /air flame freely propagating at $1 \mathrm{~atm}$ and room temperature is shown in Fig. 2. The information presented in this Figure is well documented in numerous prior studies, and the main chain branching reaction (R1) is clearly most influential. What is not clear from these results, however, is how the perturbation of the specific rate constant value at a particular temperature in the flame structure influences the laminar flame speed. The significance of this knowledge is that it indicates where uncertainties in the rate constant as a function of temperature most affect the calculated flame speed. Reaction (R1) is in general one of the most important elementary reactions in combustion chemistry, and has been extensively studied experimentally and theoretically. Recent assessments of the rate claim relatively small uncertainties over the entire temperature range of evaluation. The simplicity of the present system affords a powerful first example of the technique developed here in providing insights as to where uncertainties in this rate constant most significantly affect the primary feature of interest. We therefore start our demonstration of the methodology with a discussion of this reaction. 
Because the sensitivity coefficient, Eq. (6), is evaluated numerically, the choice of parameters in the Gaussian perturbation, Eq. (7), which results in numerically converged values of the sensitivity coefficient needs to be verified in each application. Figure 3 shows the results obtained for reaction (R1) using different values of Gaussian parameters. In this case, an acceptable convergence is observed for $T_{\sigma}=10 \mathrm{~K}$ and $T_{p} / \sqrt{2 \pi} T_{\sigma}=0.01$. For all values of the input parameters, the sensitivity coefficient for reaction $(\mathrm{R} 1)$ is observed to have a pronounced maximum at about $1210 \mathrm{~K}$, and approaches zero at low and high temperatures. As the input parameters are varied to achieve convergence, nearly the same temperature of peak sensitivity is found for even high values of $T_{\sigma}$. The asymptotic convergence of the sensitivity coefficient $\xi(T)$ to its maximum value is illustrated in Fig. 4. The two displayed curves correspond to results obtained by fixing either $T_{\sigma}$ at $10 \mathrm{~K}$ or $T_{p} / \sqrt{2 \pi} T_{\sigma}$ at 0.01 and observing the effect of variations in the remaining parameter on the value of the $\xi(T)$. A robust numerical convergence is observed in both cases. In fact, the choice of $T_{\sigma}=10 \mathrm{~K}$ and $T_{p} / \sqrt{2 \pi} T_{\sigma}=0.01$ provided converged solutions for all of the cases considered and thus, these parameters were used in all of the remaining calculations presented here.

Figure 5 presents the results of parametric calculations for a number of hydrogen/air flames with differing ambient pressures and fuel/air equivalence ratios. The solid vertical lines indicate the entire temperature range for each specific flame (i.e., from the initial room temperature to the final adiabatic flame temperature), while the shaded bars on each solid line indicate the temperature range where the value of the sensitivity coefficient $\xi(T)$ for the reaction (R1) is larger than $10 \%$ of its maximum value (as illustrated in Fig. 3). We refer here to this range of temperatures as the sensitivity window for the input parameter in question upon the observable of interest. The horizontal lines within each bar indicate the location of $\xi(T)_{\max }$. Here, we observe that the laminar flame speed is sensitive to (R1) over only a narrow sub-domain of the overall temperature range within each flame structure, and that this sub-domain changes in both extent and location with equivalence ratio and ambient pressure. The lowest temperature in each sub-domain is principally a function of pressure, with a secondary dependence on equivalence ratio at lean conditions, while the sensitivity window and temperature at 
which the sensitivity is maximum, $\xi(T)_{\max }$, shifts toward higher temperatures with increasing pressure.

The above results have immediate practical implications. At atmospheric conditions, the sensitivity window is confined to the range of about $850-1550 \mathrm{~K}$ and $\xi(T)_{\max }$ occurs at about $1210 \mathrm{~K}$. As shown in Fig. 6, the rate coefficient expressions for reaction (R1) used in several recent $\mathrm{H}_{2} / \mathrm{O}_{2}$ mechanisms $[13,14,17]$ yield nearly the same specific rate values within the temperature sensitivity window, with all correlations intersecting close to the temperature of $\xi(T)_{\max }$. The laminar flame speed predictions for atmospheric $\mathrm{H}_{2}$ /air flames are very similar for all three mechanisms and are in a good agreement with the experimental data even through different rate correlations were used. Furthermore, most of experimental measurements for this rate coefficient were conducted in shock tubes at temperatures much higher [18-22] than those within the sensitivity window for atmospheric conditions. However, differences associated with the correlations at lower temperatures can become important in the predictions. This condition can occur in flame speed experiments in low pressure flames and the differences in these correlations is also noticeable in other experimental configurations that are sensitive to the relative values of the rate constants for (R1) and (R5), $\mathrm{H}_{+}+\mathrm{O}_{2}+\mathrm{M}=$ $\mathrm{HO}_{2}+\mathrm{M}$, at temperatures below $1000 \mathrm{~K}$. Recent measurements of (R5) at temperatures below about $900 \mathrm{~K}$ require the lower rate values for (R1) predicted by the correlation used by Li et al.

At high pressures where the sensitivity window moves to higher temperatures, the disparities between the rate coefficients used in different mechanisms become more apparent, and the sensitivity window overlaps with high-temperature shock-tube measurements of this rate. As can be seen, the rate coefficient of Pirraglia et al. [20] used in the mechanism by Mueller et al. [14] becomes noticeably higher than the hightemperature consensus values of $\mathrm{Yu}$ et al. [21] used by GRI-MECH 3.0 [17] and of Hessler et al. [22] used by $\mathrm{Li}$ et al. [13] when extrapolated toward higher temperatures (Fig. 6). Mainly due to this reason, the computational results obtained with the mechanism of Mueller et al. significantly over-predicts the experimental high-pressure laminar flame speed measurements of Tse et al. [23]. Further discussions of comparisons 
of the predictions of these high-pressure flame speeds by Mueller et al. appears in Li et al. [13].

Diluent addition/substitution is commonly utilized in laminar flame research. For example, helium is substituted for nitrogen in laminar flame speed experiments to reduce flame front instabilities [23]. As shown in Fig. 7, diluent changes have significant influences on the sensitivity window for reaction (R1). For the same volume percentage of diluent, the sensitivity windows for $\mathrm{H}_{2} / \mathrm{He} / \mathrm{O}_{2}$ flames are wider than those for $\mathrm{H}_{2}$ /air flames. When more diluent is used, the sensitivity window shifts toward lower temperatures following the decrease in the adiabatic flame temperature. These observations indicate that kinetic models verified against flame speed with one diluent, may not correctly predict the flame speed with another diluents depending on differences in the correlations used to predict (R1) as a function of temperature. The temperature corresponding to the peak value of $\xi(T)$ also increases with pressure. This occurs primarily because of the dependence of radical diffusion on ambient pressure. At higher pressures, the diffusion of radicals generated in the high-temperature portion of the flame zone is less pronounced, and consequently, the maximum of the sensitivity coefficient moves to higher temperature.

As can be seen in Fig. 2, the reaction $\mathrm{H}_{2}+\mathrm{OH}=\mathrm{H}_{2} \mathrm{O}+\mathrm{H}$ also strongly affects the predicted laminar flame speed. While similar sensitivity analyses have also been conducted for this reaction, its rate coefficient has comparatively smaller uncertainties within the corresponding sensitivity windows. As a result, variation of this rate coefficient did not produce appreciable changes in the predicted laminar flame speed.

\section{Sensitivity Analysis for the $\mathrm{CO} / \mathrm{H}_{2}$ Combustion Mechanism}

The $\mathrm{CO} / \mathrm{H}_{2}$ flame system represents the next more complex dependence of flame speed on combustion chemistry, and laminar flame speed studies for this system have been conducted for selected $\mathrm{CO} / \mathrm{H}_{2}$ ratios $[24,25]$. As shown in Fig. 8, it is well recognized that the burning velocity of $\mathrm{CO} / \mathrm{H}_{2}$ flames is very sensitive to the rate constant of $\mathrm{CO}$ oxidation by $\mathrm{OH},(\mathrm{R} 2)$, for $\mathrm{CO} / \mathrm{H}_{2}$ volume ratios greater than one. Although the conventional sensitivity of the flame speed to (R1) is considerably reduced for these conditions, the functional character and temperature windows defined by $\xi(T)$ for reaction 
(R1) were found to be similar to those observed in $\mathrm{H}_{2} /$ air flames. The temperaturedependent sensitivity coefficient $\xi(T)$ for reaction (R2) is very interesting in that there are two maxima in the function at rich conditions that collapse into a single peak at lean conditions (Fig. 9). The sensitivity window for (R2) is much wider and extends to much lower temperatures than for reaction (R1) (Fig. 5).

Sensitivity windows for a range equivalence ratios and selected $\mathrm{CO} / \mathrm{H}_{2}$ ratios for reaction (R2) are presented in Fig. 10. The sensitivity patterns presented in this Figure provide immediate and direct guidance regarding the choice of the rate coefficient correlations appropriate for the specific rate of (R2) as a function of temperature that are more appropriate for the prediction of the flame speed for these flames. Reaction (R2) is a chemical activation process well known to exhibit a strong non-Arrhenius behavior [26]. As one of the most important elementary reactions in combustion chemistry, it has been studied extensively, and there is a large body of both experimental and theoretical results available in the literature. Figure 11 shows a compilation of most recent literature data. Of importance is that most of reported experimental data are from high-temperature shock-tube studies, and the vast majority of these data are outside of the sensitivity window for this reaction shown in Fig. 10. On the low-temperature side, there are much fewer data points, however, the sensitivity of the flame speed to the specific rate constant at these temperatures still remains high. Two recent RRKM fits (Yu [27] and Senosian et al. [28]) are intended to yield the rate coefficient for (R2) over the entire range of relevant temperatures. However, both resulting correlations were primarily calibrated against high-temperature shock-tube data and significantly over-predict all available experimental determinations of this rate constant at intermediate temperatures around 900 $\mathrm{K}$. These temperatures are not only within the sensitivity window for this reaction but also encompass the temperatures at which $\xi(T)_{\max }$ occurs as flame parameters of pressure, equivalence ratio, and $\mathrm{CO} / \mathrm{H}_{2}$ ratio are varied. If one assumes that the theoretical fits misrepresent the specific rate of this reaction by comparison with the (presumably) more accurate experimental data at these temperatures, one would expect $\mathrm{CO} / \mathrm{H}_{2}$ flame speeds to be over-predicted with the reaction models based on these rate parameters. Indeed, as shown in Fig. 12, GRI-MECH 3.0 which used the values of $\mathrm{Yu}$ [27] over-predicts the experimentally-measured $\mathrm{CO} / \mathrm{H}_{2} /$ air laminar flame speeds of McLean et al [24]. Based 
upon the observations reported here, $\mathrm{Li}$ et al. [29] recently performed a modified Arrhenius fit of all experimental data shown in Fig. 11, weighted by reported or estimated experimental errors. The resulting correlation is presented in Fig. 11. It should be emphasized here, as it is also noted in Li et al., that error weighting of the experimental data is absolutely essential because at lower temperatures, the resulting fit gravitates toward the data of Ravishankra et al. [30]. However, if equal weighting is assumed, the correlated fit would be closer to the flame data of Vandooren et al. [31], measurements that are known to have much larger uncertainties. We also note that the resulting fit is very close to the theoretical expression of Troe [32] at low and intermediate temperatures. At high temperatures, however, the empirical fit produces lower values, consistent with the experimental data of Lissianski et al. [33]. Finally, the substitution of this correlation for that used in the GRI-Mech 3.0 mechanism for the specific rate constant of (R2) brings the model predictions into excellent agreement with the experimental data (Fig. 12). Further comparisons of predictions of combustion phenomena involving $\mathrm{CO}$ oxidation kinetics using this correlation are discussed elsewhere [29].

Similar to the reaction (R2), the sensitivity windows for reaction $\mathrm{HCO}+\mathrm{M}=\mathrm{CO}$ $+\mathrm{H}+\mathrm{M}$, (R3) (Fig. 13), and $\mathrm{HCO}+\mathrm{O}_{2}=\mathrm{CO}+\mathrm{HO}_{2}$, (R4), are very wide and start at a very low temperature. In $\mathrm{CO} / \mathrm{H}_{2}$ flames, $\mathrm{HCO}$ is formed at very early stages by reaction of $\mathrm{CO}$ and $\mathrm{H}$ atom, where $\mathrm{H}$ can be transported by diffusion from the high temperature flame regions to the initial flame regions where $\mathrm{CO}$, the initial reactant, is present. These reactions are not only of significance here, but are of essential importance in predicting flame speeds for fuels where the principal source of $\mathrm{HCO}$ is $\mathrm{CH}_{2} \mathrm{O}$, as discussed below.

\section{Sensitivity Analysis for Methanol Flames}

For methanol flames, the flame speed is most sensitive to $\mathrm{HCO}+\mathrm{M}=\mathrm{CO}+\mathrm{H}+$ $\mathrm{M}$ (Fig. 14). In contrast to $\mathrm{CO}$ flames, the temperature dependent sensitivity for this reaction and the competing reaction, $\mathrm{HCO}+\mathrm{O}_{2}=\mathrm{CO}+\mathrm{HO}_{2}$, are located at very high temperatures (Fig. 15) in comparison to those for reactions (R1) and (R2). In methanol flames, the major source for $\mathrm{HCO}$ is $\mathrm{CH}_{2} \mathrm{O}$, which is generated in the high-temperature reaction zone. Note that the sensitivity window for reaction (R2) in hydrocarbon flame 
systems displayed in Fig. 16 is considerably narrower than for CO flames, primarily because $\mathrm{CO}$ is an intermediate species formed at higher temperatures in the flame zone (not an initial reactant). Due to the different origins of $\mathrm{CO}$ and $\mathrm{HCO}$, the temperature dependent sensitivity spectrums of the $\mathrm{CO}$ flame will generally differ from those for hydrocarbon fuels.

As in the case of the comparisons of existing rate correlations for reactions (R1) and (R2) and their significance to predicting flame speeds, one finds similar implications as to the temperature ranges over which specific rate constant correlations for (R3) and (R4) most affect flame speed predictions. These differences point to a need to develop a weighted correlation for the specific rate constant measurements of (R3) to more accurately predict flame speed results as well as other kinetic phenomena. The specific reaction data available for (R4) are not sufficient to perform such a correlation over a wide temperature range, and thus a specific correlation of more limited data must be accepted. Details resulting from these procedures as well as comparisons of the revised mechanistic behavior against a wide range of kinetic experiments are presented in $\mathrm{Li}$ et al. [29].

\section{Sensitivity Analysis for the $\mathrm{C}_{3} \mathrm{H}_{8}$ Combustion Mechanism}

Propane is generally considered to be the smallest hydrocarbon molecule with combustion characteristics similar to larger hydrocarbon fuels. Because the flame speeds for molecules larger than $\mathrm{C}_{3}$ are primarily controlled by the $\mathrm{C}_{3}$ sub-mechanism (e.g. [38, 39]), it is reasonable to expect that for large molecule hydrocarbon fuels, that conventional sensitivity, temperature-dependent sensitivity, and temperature sensitivity window patterns for small species interactions will be similar to those found for propane flames. Therefore, we use propane/air flame speed cases here as a final application example.

For propane/air flames, temperature-dependent sensitivity analyses were performed on the five reactions most important to determining flame speed (Fig. 17): $\mathrm{H}+$ $\mathrm{O}_{2}=\mathrm{OH}+\mathrm{O}(\mathrm{R} 1), \mathrm{CO}+\mathrm{OH}=\mathrm{CO}_{2}+\mathrm{H}(\mathrm{R} 2), \mathrm{HCO}+\mathrm{M}=\mathrm{CO}+\mathrm{H}+\mathrm{M}(\mathrm{R} 3)$, and $\mathrm{HCO}$ $+\mathrm{O}_{2}=\mathrm{CO}+\mathrm{HO}_{2}(\mathrm{R} 4)$, and $\mathrm{H}+\mathrm{O}_{2}(+\mathrm{M})=\mathrm{HO}_{2}(+\mathrm{M})$ (R5) as identified by conventional sensitivity analyses. The results are compiled in Figs $18-22$, where the 
color changes in the bar indicate the sign change of the sensitivity coefficient. As compared to the same reaction in $\mathrm{CO} / \mathrm{H}_{2}$ and hydrogen flames, it is again noted that the sensitivity windows are narrower and do not extend to as low temperatures as in either of these cases. It is also interesting to note that for reactions (R2), (R4) and (R5) the sensitivity may change sign at high pressure and fuel-rich conditions (Fig. 20 - 22). Although $\mathrm{HO}_{2}$ is not important at low pressure conditions, at higher pressures the enhanced formation rate of $\mathrm{HO}_{2}$ results in production of significant quantities of $\mathrm{H}_{2} \mathrm{O}_{2}$, which in turn can decompose to produce $\mathrm{OH}$. As a result, the sensitivities for reactions such as (R2) and (R5) may change sign at those conditions.

\section{Sensitivity Coefficients and Reaction Rates}

One might suspect that the reported temperature-dependent sensitivity coefficients with respect to a specific reaction rate coefficient can be approximately correlated with the corresponding reaction rates (at least for the laminar flame speed cases considered here). Figure 23 shows comparisons of sensitivity coefficients and the net reaction rates for (R1) and (R2). Indeed, the rate curves closely follow the corresponding sensitivity coefficients for the $\mathrm{C}_{3} \mathrm{H}_{8} /$ air case. Clearly, in such cases, one can simply evaluate the reaction rates to approximately identify the sensitivity windows instead of following a complex series of steps involved in the evaluation of the temperature sensitivity coefficients themselves. A similar observation was reported by Rumminger et al [9]. However, this reasoning does not hold for all circumstances. As evidenced by the example of (R2) for $\mathrm{CO} / \mathrm{H}_{2}$ flame, the reaction rate, while closely following the corresponding sensitivity coefficient at lower temperatures, extends to much higher temperatures where the actual sensitivity is nearly zero. Therefore, the sensitivity window estimated based on the reaction rate curve would be substantially wider than the exact result based on the temperature sensitivity analysis. Furthermore, the analyses for reaction (R1) in cases of $\mathrm{H}_{2}$ and $\mathrm{CO} / \mathrm{H}_{2}$ flames show distinct differences between the net reaction rate and the temperature sensitivity coefficient results. While similarity shaped, the curves exhibit peaks at very different temperatures, almost $500 \mathrm{~K}$ apart with the peak in the sensitivity coefficient occurring at lower temperature. Because the sensitivity window width for these cases is about $700 \mathrm{~K}$, the sensitivity window for (R1) estimated 
based on the reaction rate curve for these cases would not only be misleading but also would have almost no overlap with the actual sensitivity window.

\section{Sensitivity Analysis for Binary Diffusion Coefficient}

The temperature dependent sensitivity coefficients for binary diffusion coefficients can be determined in a manner similar to that used in investigating kinetic parameters. The temperature dependent sensitivity features of binary diffusion coefficients are demonstrated here using $\mathrm{H}_{2}$ flames.

Figures 24 and 25 show temperature dependent sensitivity of $\mathrm{H} / \mathrm{He}$ and $\mathrm{H} / \mathrm{H}_{2} \mathrm{O}$ binary diffusion coefficients for laminar flame speeds of $\mathrm{H}_{2} / \mathrm{O}_{2} / \mathrm{He}$ mixtures. The sensitivity of binary diffusion coefficients of $\mathrm{H}$-atom to $\mathrm{H}_{2}$, and $\mathrm{O}_{2}$, of $\mathrm{He}$ to $\mathrm{H}_{2}$ and $\mathrm{O}_{2}$ were also studied. The observed features are essentially the same as those shown in Figs 24-25, and detailed results are therefore not reported here. Similar to the case of specific rate analyses, the sensitivity with respect to a particular binary diffusion coefficient correlation is also concentrated in a narrow temperature range and may change sign. The shape of the computed $\xi(T)$ function is a result of complex reaction/transport interactions within the flame structure. Figure 26 shows the comparison of the normalized sensitivity spectrum of $\mathrm{H} / \mathrm{He}$ diffusion coefficient, (R1) reaction rate and the $\mathrm{H}$-atom concentration gradient at the indicated condition. At lower temperatures, an increase in the diffusion

coefficient causes an enhanced transport of $\mathrm{H}$ atoms toward the cold region where they do not contribute to chain branching kinetics (primarily, via: (R1), $\mathrm{H}+\mathrm{O}_{2}=\mathrm{OH}+\mathrm{O}$ ). Consequently, the sensitivity with respect to the $\mathrm{H} / \mathrm{He}$ binary diffusion coefficient is negative. As the temperature increases, the $\mathrm{H} / \mathrm{He}$ diffusion sensitivity becomes positive and peaks close to the point where the rate of (R1) reaches a maximum. Here, the diffusive flux of $\mathrm{H}$ atoms to the region where chain branching is active results in and an increase in the flame speed. At even higher temperatures, the sensitivity with respect to the $\mathrm{H} / \mathrm{He}$ binary diffusion coefficient goes through zero again (around the point where $\mathrm{H}$ concentration has its peak, indicative of directional change in $\mathrm{H}$ diffusion flux). From this point, the diffusion flux carries $\mathrm{H}$ atoms away from the chain-branching region toward the post-flame zone, and the sensitivity becomes negative again. The temperature 
range and sensitivity value of this non-monotonic shape may cause the overall binary diffusion coefficient sensitivity to even change sign with initial conditions.

The non-monotonic behavior of binary diffusion coefficient sensitivity with respect to temperature has significant implications for detailed flame modeling. For example, Middha et al. [8]) recently reported improved values of $\mathrm{H} / \mathrm{He}$ binary diffusion coefficient which are generally higher than those computed with the CHEMKIN II database over the entire temperature range of interest (Fig. 24). However, it was also reported that the resulting flame speeds did not change significantly. One of the reasons is clearly the relatively small difference (as compared to uncertainties in reaction rate coefficients) between the TRANFIT expression and the result of Middha et al. Another reason discovered in the present study is that the difference in binary diffusion coefficient (which is uniformly positive with slight increase with the temperature) may be compensated by the sensitivity sign change with the temperature, resulting in a minor difference in predicted flame speed.

\section{Summary and Conclusions}

We have demonstrated here a novel applied sensitivity analysis method using perturbation with a temperature-dependent Gaussian-shaped profile to determine the range of temperatures over which a predicted observable is sensitive to a particular input parameter. To demonstrate the methodology and utility of the technique, we presented results obtained in analyzing the temperature sensitivity of flame speed predictions to the most significant reactions in $\mathrm{H}_{2}, \mathrm{H}_{2} / \mathrm{CO}, \mathrm{CH}_{3} \mathrm{OH}$ and $\mathrm{C}_{3} \mathrm{H}_{8}$ oxidation systems. We also demonstrated the methodology in analyzing the effects of temperature dependence of binary diffusion coefficients on predicted $\mathrm{H}_{2} / \mathrm{He} / \mathrm{O}_{2}$ flames. The sensitivity parameters for almost all reactions are very temperature dependent. Our results also explain the cause of the sign shift in binary diffusion coefficient to burning velocities. The temperature dependent sensitivity approach not only provides new insights for flame modeling, it also may serve as a tool to identify the most significant temperature range in which parameters should be experimentally and theoretically studied to reduce uncertainties important to a particular set of predictions. Examples were also described 
to apply the temperature dependent sensitivity analysis in helping to determine reaction rate for elementary reactions.

\section{Acknowledgments}

This work is supported by the Chemical Sciences, Geosciences and Biosciences Division, Office of Basic Energy Sciences, Office of Science, U.S. Department of Energy under Grant No. DE-FG02-86ER13503.

\section{Bibliography}

1. Frank, P. M. Introduction to System Sensitivity Theory; Academic Press: New York, 1978.

2. Rabitz, H. Comput Chem 1981, 5, 167-180.

3. Yetter, R.; Eslava, L. A; Dryer, F. L.; Rabitz, H. J Phys Chem, 1984, 88, $1497-$ 1507.

4. Miller, J. A.; Branch, M. C.; McLean, W. J.; Chandler, D. W.; Smooke, M. D.; Lee, R. J. Proc Combust Inst, 1984, 20, 673-684.

5. Yetter, R.; Dryer, F. L.; Rabitz, H. Combust Flame, 1985, 59, 107-133.

6. Mishra, M. R.; Yetter, R.; Reuven, Y.; Rabitz, H.; Smooke M. D. Intl J Chem Kinet, 1994, 26, 437-453.

7. Yang, Z.; Yang, B.; Wang, H. 2nd joint meeting of the U.S. sections of the Combustion Institute, Oakland, CA 2001, Paper No. 237.

8. Middha, P.; Yang, B. H.; Wang, H. Proc Combust Inst, 2002, 29, 1361-1369.

9. Rumminger, M. D.; Babushok, V.;I.; Linteris, G. T. Proc Combust Inst, 2002, 29, 329-336.

10. Kee, R. J.; Rupley, F. M.; Miller, J. A. CHEMKIN II: A Fortran Chemical Kinetics Package for the Analysis of Gas Phase Chemical Kinetics, Sandia Report No. SAND89-8009, Sandia National Laboratories, 1989.

11. Kee, R. J.; Dixon-Lewis, J.; Warnatz, J.; Coltrin, J. A.; Miller, J. A. A Fortran Program for Modeling Steady Laminar One-Dimensional Premixed Flames, Sandia Report No. SAND85-8240, Sandia National Laboratories, 1985. 
12. Davis, S. G.; Mhadeshwar, A. B.; Vlachos, D. G.; Wang, H. Int J Chem Kinet, 2004, 36, 94-106.

13. Li, J.; Zhao, Z.; Kazakov, A.; Dryer, F. L. Int J Chem Kinet, 2004 In press.

14. Mueller, M. A.; Yetter, R. A.; Dryer, F. L. Int J Chem Kinet, 1999, 31, 705-724.

15. Held, T. J.; Dryer, F. L. Int J Chem Kinet, 1998, 30, 805-830.

16. Qin, Z.; Lissianski, V.; Yang, H.; Gardiner, Jr.,W. C.; Davis, S. G.; Wang, H. Proc Combust Inst, 2000, 28, 1663-1669.

17. Smith, G. P.; Golden, D. M.; Frenklach, M.; Eiteneer, B.; Goldenberg, M.; Bowman, C. T.; Hanson, R. K.; Song, S.; Gardiner Jr., W. C.; Lissianski, V. V.; Qin, Z. http://www.me.berkeley.edu/gri_mech/, 1999.

18. Masten, D. A.; Hanson, R. K.; Bowman, C. T. J Phys Chem, 1990, 94, 71197128.

19. Du, H.; Hessler, J. P. J Chem. Phys. 1992, 96, 1077-1092.

20. Pirraglia, A. N.; Michael, J. V.; Sutherland, J. W.; Klemm, R. B. J Phys Chem, 1989, 93, 282-291.

21. Yu, C-L.; Frenklach, M.; Masten, D. A.; Hanson, R. K.; Bowman, C. T. J Phys Chem, 1994, 98, 4770-4771.

22. Hessler, J. P. J Phys Chem A, 1998, 102, 4517-4526.

23. Tse, S. D.; Zhu, D. L.; Law, C. K. Proc Combust Inst, 2000, 28, 1793-1800.

24. McLean, I. C.; Smith, D. B.; Taylor, S. C. Proc Combust Inst, 1994, 25, 749-757.

25. Huang, Y.; Sung, C. J.; Eng, J. A. Third Joint Meeting of the U.S. Sections of the Combustion Institute, Chicago, IL, 2003.

26. Dryer, F. L., Glassman, I., Naegeli, D., Combust Flame, 1971, 17, 270-272.

27. Yu, C. L. Chemical Kinteics of Reaction Systems, $\mathrm{CO}+\mathrm{OH}$ and $\mathrm{CH}_{3}+\mathrm{O}_{2}$, Ph.D. thesis, Department of Materials Science and Engineering, the Pennsylvania State University, 1996.

28. Senosiain, J. P.; Musgrave, C. B.; Golden, D. M. Int J Chem Kinet, 2003, 35, 464474.

29. Li, J.; Zhao, Z.; Kazakov, A.; Dryer, F. L.; Scire, J. J., Jr. Int J Chem Kinet, 2004 Submitted. 
30. Ravishankara, A. R.; Thompson, R. L. Chemical Physics Letters, 1983, 99, 377381.

31. Vandooren, J.; Peeters, J.; Van Tiggelen, P. J. Proc Combust Inst, 1975, 15, 745753.

32. Troe, J. Proc Combust Inst, 1998, 27, 167-176.

33. Lissianski, V.; Yang, H.; Qin, Z.; Mueller, M. R.; Shin, K. S.; Gardiner Jr., W. C. Chemical Physics Letters, 1995, 240, 57-62.

34. Wooldridge, M. S.; Hanson, R. K.; Bowman, C. T. Proc Combust Inst, 1994, 25, 741-748.

35. Westenberg, A. A.; deHaas, N. J Chem Phys, 1973, 58, 4061-4065.

36. Wooldridge, M. S.; Hanson, R. K.; Bowman, C. T. Int J Chem Kinet, 1996, 28, 361-372.

37. Golden, D. M.; Smith, G. P.; McEwen, A. B.; Yu, C.-L.; Eiteneer, B.; Frenklach, M.; Vaghjiani, G. L.; Ravishankara, A. R.; Tully F. P. J Phys Chem A, 1998, 102, 8598-8606.

38. Zhao, Z.; Li, J.; Kazakov, A.; Dryer, F. L. Combust Sci Technol, 2004, In press.

39. Zhao, Z.; Li, J.; Kazakov, A.; Zeppieri, S. P.; Dryer, F. L. Combust Sci Technol, 2004, In press.

40. Paul, P. H. DRFM: A New Package for the Evaluation of Gas-Phase Transport Properties, Sandia report SAND98-8203, 1998.

41. Kee, R. J.; Dixon-Lewis, J.; Warnatz, J.; Coltrin, J.;A.; Miller, J. A. A Fortran Computer Code for the Evaluation of Gas Phase, Multicomponent Transport Properties, Sandia Report No. SAND86-8284, Sandia National Laboratories, 1989. 


\section{Figure Captions}

Figure 1 Schematic representation of the use of global and local perturbations to obtain sensitivity coefficients defined by Eq. (4) and Eq. (6).

Figure 2 Conventional sensitivity analysis for $\mathrm{H}_{2}$ /air laminar premixed flame at $298 \mathrm{~K}, 1$ $\mathrm{atm}$ and equivalence ratios of 1.0 and 2.0.

Figure 3 Sensitivity coefficient for reaction (R1), $\mathrm{H}+\mathrm{O}_{2}=\mathrm{OH}+\mathrm{O}$, in $\mathrm{H}_{2}$ kinetic model at stoichiometric, $1 \mathrm{~atm}, 298 \mathrm{~K}$ with different $T_{\sigma}$ and $T_{p} / \sqrt{2 \pi} T_{\sigma}$ : (a) $T_{\sigma}=2500 \mathrm{~K}$ and $T_{p} / \sqrt{2 \pi} T_{\sigma}=0.01$; ( b) $T_{\sigma}=500 \mathrm{~K}$ and $T_{p} / \sqrt{2 \pi} T_{\sigma}=0.01$; (c) $T_{\sigma}=100 \mathrm{~K}$ and $T_{p} / \sqrt{2 \pi} T_{\sigma}=0.01$; (d) $T_{\sigma}=10 \mathrm{~K}$ and $T_{p} / \sqrt{2 \pi} T_{\sigma}=1$; (e) $T_{\sigma}=10 \mathrm{~K}$ and $T_{p} / \sqrt{2 \pi} T_{\sigma}=$ 0.01 ; (f) $T_{\sigma}=10 \mathrm{~K}$ and $T_{p} / \sqrt{2 \pi} T_{\sigma}=10^{-4}$.

Figure 4 The effect of the perturbation magnitude and width on the obtained sensitivity peak value for (R1) in $\mathrm{H}_{2}$ kinetic model at stoichiometric conditions, 1 atm and $298 \mathrm{~K}$.

Figure 5 The sensitivity temperature window for reaction rate of (R1) in $\mathrm{H}_{2}$ kinetic model. The numbers in the figure refer to equivalence ratio.

Figure 6 Rate coefficient of (R1), $\mathrm{H}+\mathrm{O}_{2}=\mathrm{OH}+\mathrm{O}$, used in different $\mathrm{H}_{2}$ kinetic models.

Figure 7 Sensitivity for (R1), $\mathrm{H}+\mathrm{O}_{2}=\mathrm{OH}+\mathrm{O}$, in $\mathrm{H}_{2}$ kinetic model for different diluents at equivalence ratio $2.0\left(\mathrm{~N}_{2}: \mathrm{O}_{2} / \mathrm{N}_{2}=1 / 3.76, \mathrm{He} 1: \mathrm{O}_{2} / \mathrm{He}=1 / 3.76, \mathrm{He} 2: \mathrm{O}_{2} / \mathrm{He}=\right.$ 1/7.52, $\left.\mathrm{He} 3: \mathrm{O}_{2} / \mathrm{He}=1 / 11.28\right)$.

Figure 8 Conventional sensitivity analysis for $\mathrm{H}_{2} / \mathrm{CO}$ flame at $298 \mathrm{~K}, 1 \mathrm{~atm}$ and equivalence ratio 1.0 .

Figure 9 Sensitivity coefficient for (R2), $\mathrm{CO}+\mathrm{OH}=\mathrm{HO}_{2}+\mathrm{H}$, in $\mathrm{CO} / \mathrm{H}_{2}$ kinetic model at $1 \mathrm{~atm}$ and $298 \mathrm{~K}\left(\mathrm{CO} / \mathrm{H}_{2}=95 / 5\right)$.

Figure 10 Sensitivity coefficient for (R2), $\mathrm{CO}+\mathrm{OH}=\mathrm{HO}_{2}+\mathrm{H}$, in $\mathrm{CO} / \mathrm{H}_{2}$ flames at 298 $\mathrm{K}$, atmospheric pressure. Black and white horizontal lines within each bar indicate locations of first (highest) and second peak values, respectively (see Fig. 9). The numbers in the figure refer to equivalence ratio.

Figure 11 Rate coefficient of (R2), $\mathrm{CO}+\mathrm{OH}=\mathrm{HO}_{2}+\mathrm{H}$. The left-hand figure shows the compilation of all recent literature data, and the right-hand figure presents only the data within the sensitivity window for this reaction. 
Figure 12 Laminar flame speed of $\mathrm{CO} / \mathrm{H}_{2} /$ air mixture $\left(\mathrm{CO} / \mathrm{H}_{2}=95 / 5\right)$ at 1 atm and 298 K.

Figure 13 Sensitivity coefficient for ( $\mathrm{R} 3$ ), $\mathrm{HCO}+\mathrm{M}=\mathrm{CO}+\mathrm{H}+\mathrm{M}$, in $\mathrm{CO} / \mathrm{H}_{2}$ kinetic model at $1 \mathrm{~atm}$ and $298 \mathrm{~K}$. Black and white line notations within shaded bars are the same as in Fig. 10. The numbers in the figure refer to equivalence ratio.

Figure 14 Conventional sensitivity analysis for stoichiometric methanol/air flame at 1 atm and $298 \mathrm{~K}$.

Figure 15 Sensitivity coefficient for (R3), $\mathrm{HCO}+\mathrm{M}=\mathrm{CO}+\mathrm{H}+\mathrm{M}$, and (R4), $\mathrm{HCO}+$ $\mathrm{O}_{2}=\mathrm{CO}+\mathrm{HO}_{2}$, in methanol kinetic model at $1 \mathrm{~atm}$ and $298 \mathrm{~K}$.

Figure 16 Sensitivity for reaction rate of (R2), $\mathrm{CO}+\mathrm{OH}=\mathrm{CO}_{2}+\mathrm{H}$, in methanol kinetic model at 1 and $10 \mathrm{~atm}, 298 \mathrm{~K}$. The numbers in the figure refer to equivalence ratio.

Figure 17 Conventional sensitivity analysis for stoichiometric propane/air flame at $1 \mathrm{~atm}$ and $298 \mathrm{~K}$.

Figure 18 Sensitivity coefficient for ( $\mathrm{R} 2), \mathrm{CO}+\mathrm{OH}=\mathrm{CO}_{2}+\mathrm{H}$, in propane/air flames at 1 and $10 \mathrm{~atm}$. The numbers in the figure refer to equivalence ratio.

Figure 19 Sensitivity coefficient for $(\mathrm{R} 1), \mathrm{H}+\mathrm{O}_{2}=\mathrm{OH}+\mathrm{O}$, in propane/air flames at 1 and $10 \mathrm{~atm}$. The numbers in the figure refer to equivalence ratio.

Figure 20 Sensitivity coefficient for (R5), $\mathrm{H}+\mathrm{O}_{2}+\mathrm{M}=\mathrm{HO}_{2}+\mathrm{M}$, in propane/air flames at initial $T=298$ and $650 \mathrm{~K}, 1$ and $10 \mathrm{~atm}$ pressure. The numbers in the figure refer to equivalence ratio.

Figure 21 Sensitivity coefficient for ( $\mathrm{R} 3), \mathrm{HCO}+\mathrm{M}=\mathrm{CO}+\mathrm{H}+\mathrm{M}$, in propane/air flames at initial $\mathrm{T}=298$ and $650 \mathrm{~K}, 1$ and $10 \mathrm{~atm}$ pressure. Black and white line notations within shaded bars are the same as in Fig. 10. The numbers in the figure refer to equivalence ratio.

Figure 22 Sensitivity coefficient for (R4), $\mathrm{HCO}+\mathrm{O}_{2}=\mathrm{CO}+\mathrm{HO}_{2}$, in propane/air flames at initial $\mathrm{T}=298$ and $650 \mathrm{~K}, 1$ and $10 \mathrm{~atm}$ pressure. Black and white line notations within shaded bars are the same as in Fig. 10. The numbers in the figure refer to equivalence ratio.

Figure 23 Comparison of temperature-dependent sensitivity coefficients with the corresponding net reaction rates; solid lines - sensitivity coefficient, dotted lines - net reaction rate. All flame calculations were performed at stoichiometric conditions at $1 \mathrm{~atm}$ and $298 \mathrm{~K}$. For $\mathrm{CO} / \mathrm{H}_{2} /$ air flame, $\mathrm{CO} / \mathrm{H}_{2}$ volumetric ratio is 95:5.

Figure 24 Sensitivity of $\mathrm{H} / \mathrm{He}$ binary diffusion coefficient on $\mathrm{H}_{2} / \mathrm{He} / \mathrm{O}_{2}$ laminar flame speeds at equivalence ratio 1.5, and the diffusion coefficient of $\mathrm{H}-\mathrm{He}$ for different expressions. 
Figure 25 Sensitivity coefficient for $\mathrm{H} / \mathrm{H}_{2} \mathrm{O}$ binary diffusion coefficient in $\mathrm{H}_{2} / \mathrm{He} / \mathrm{O}_{2}$ flame at equivalence ration 1.5.

Figure 26 Sensitivity coefficient for $\mathrm{H} / \mathrm{He}$ binary diffusion coefficient (dotted line), reaction rate of (R2), $\mathrm{H}+\mathrm{O}_{2}=\mathrm{OH}+\mathrm{O}$, (solid line) and $\mathrm{H}$ concentration gradient (dashed line) for $\mathrm{H}_{2} / \mathrm{He} / \mathrm{O}_{2}\left(\mathrm{He} / \mathrm{O}_{2}=23 / 2\right)$ flame at equivalence ratio 1.5 and 20 atm pressure. All presented quantities are normalized by the respective maximum values. 


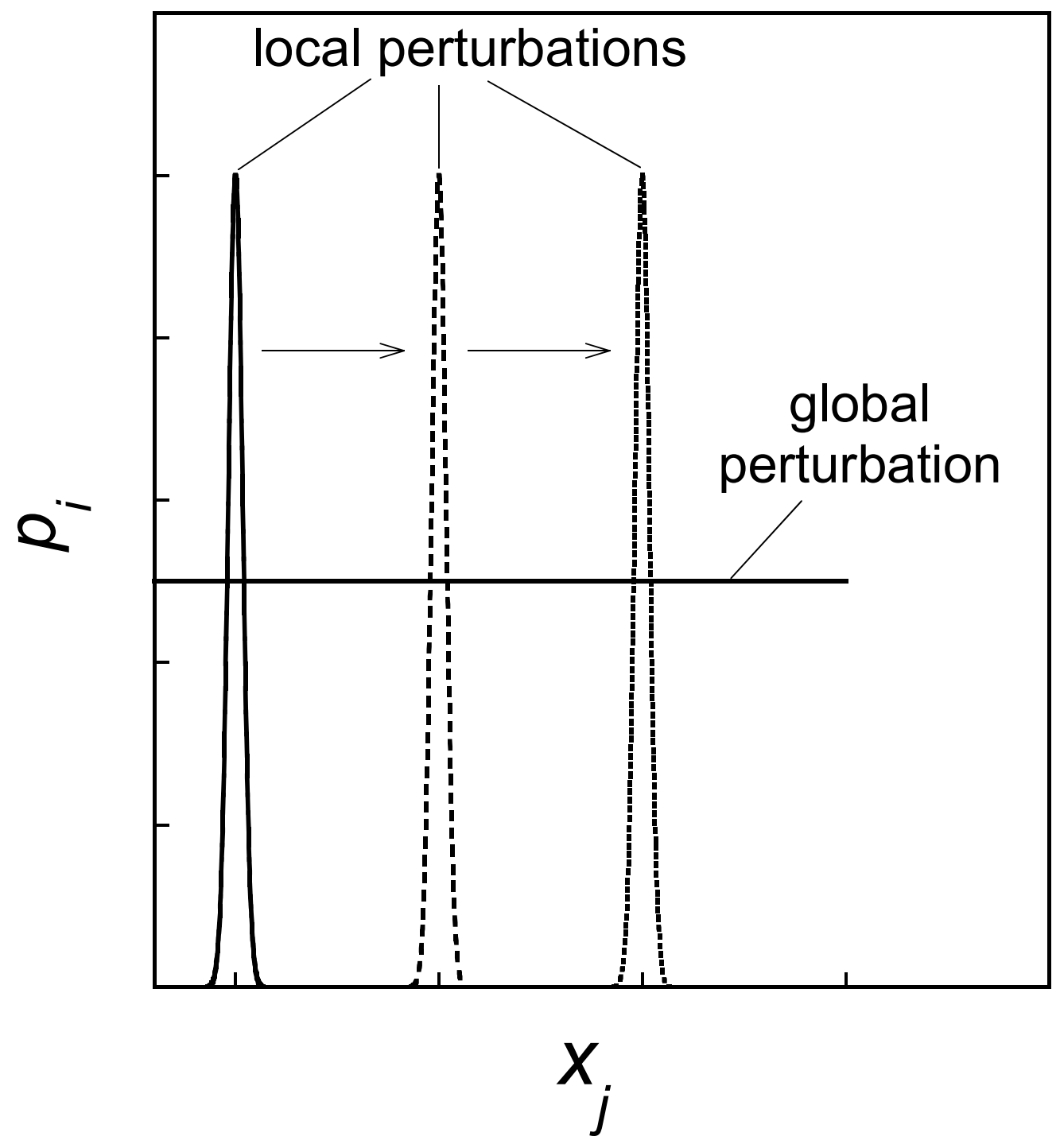

Figure 1 


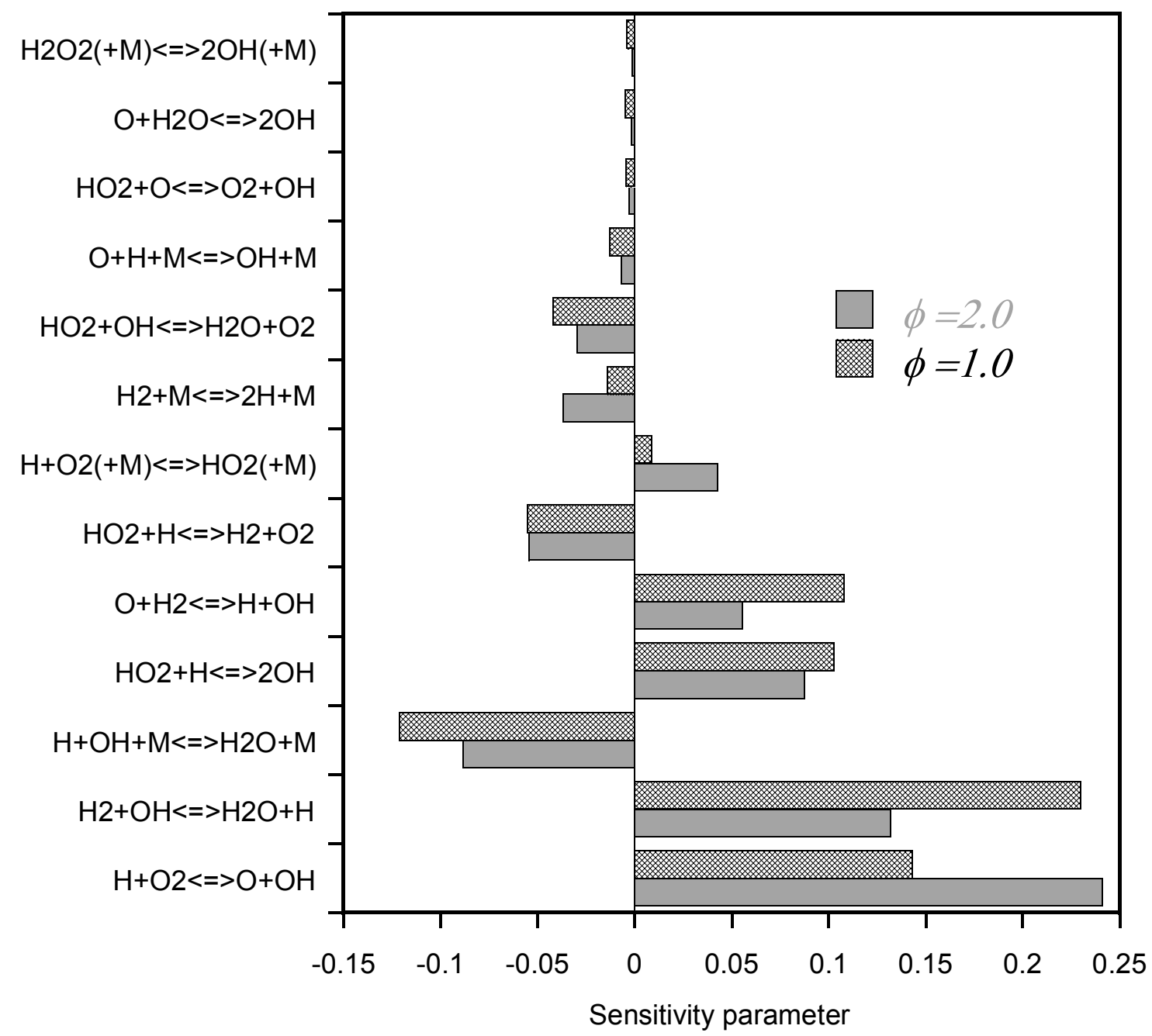

Figure 2 


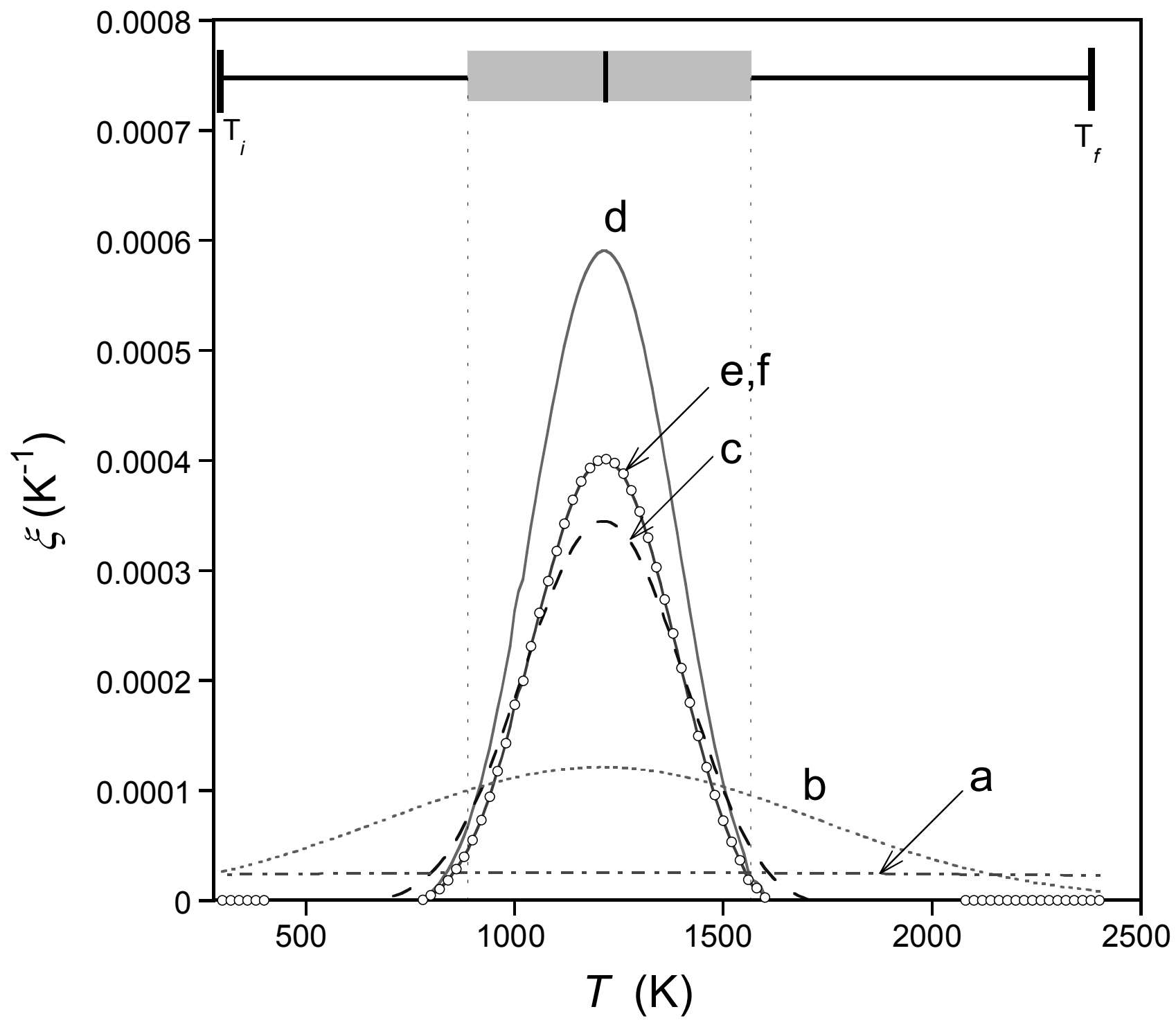

Figure 3 


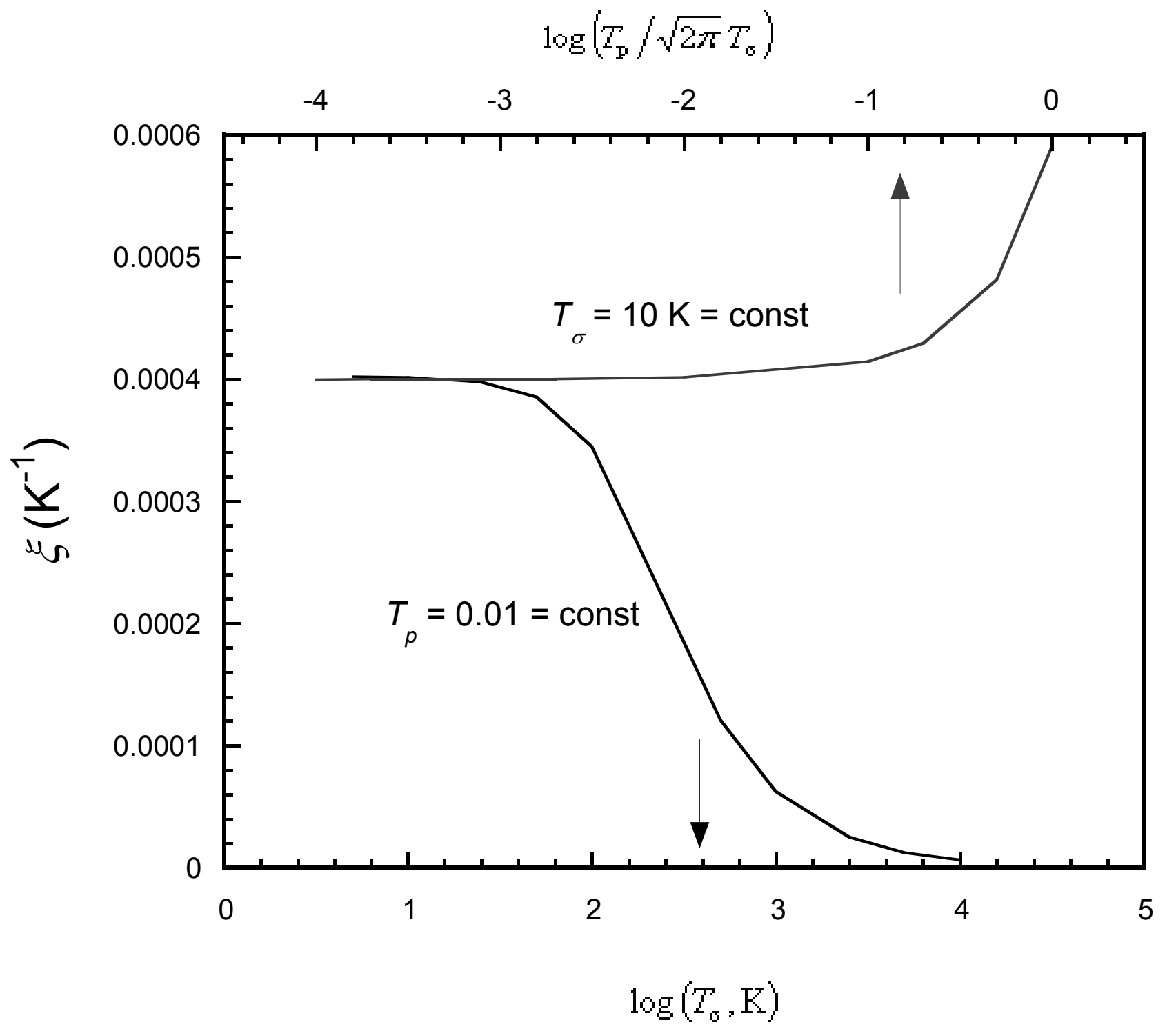

Figure 4 


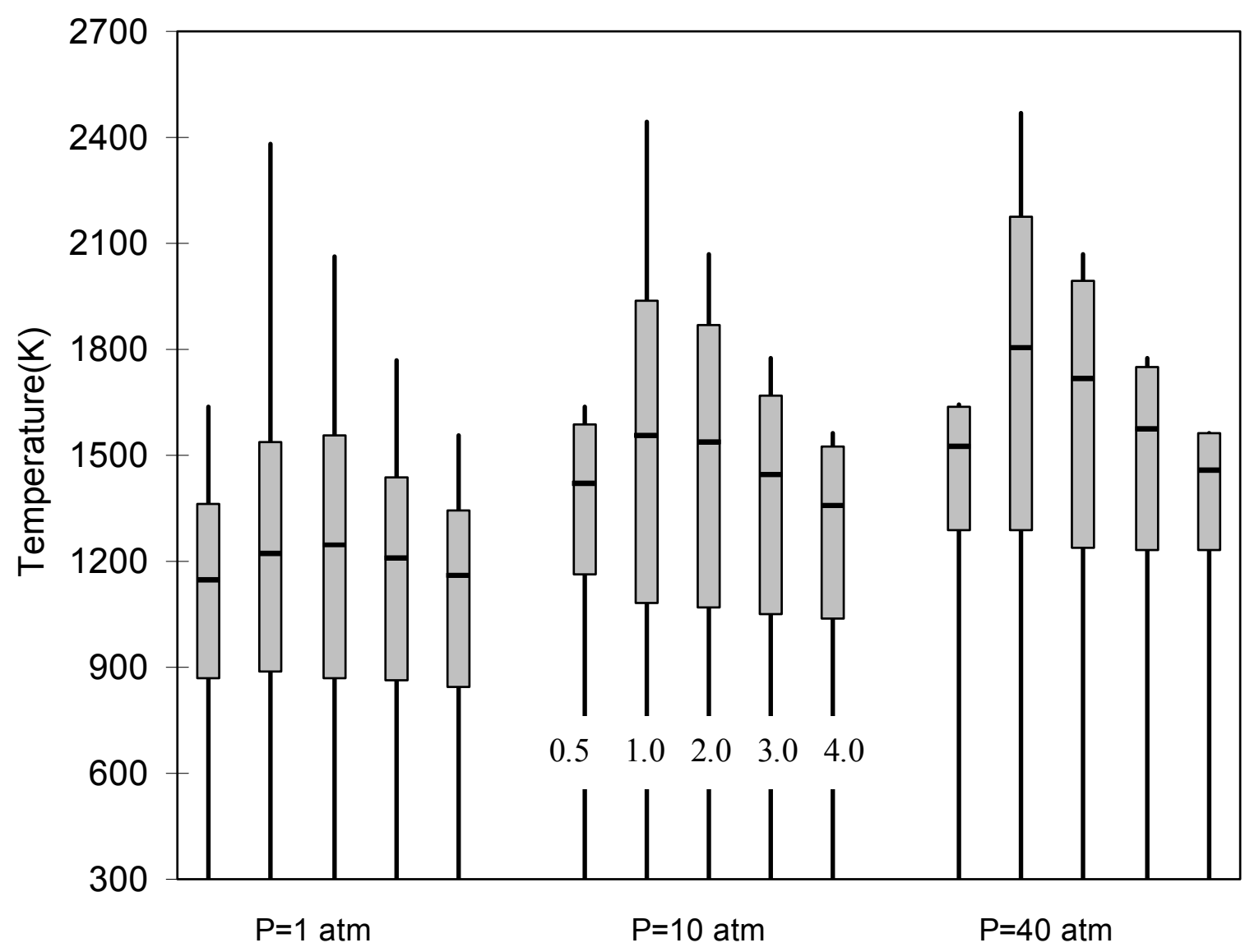

Figure 5 


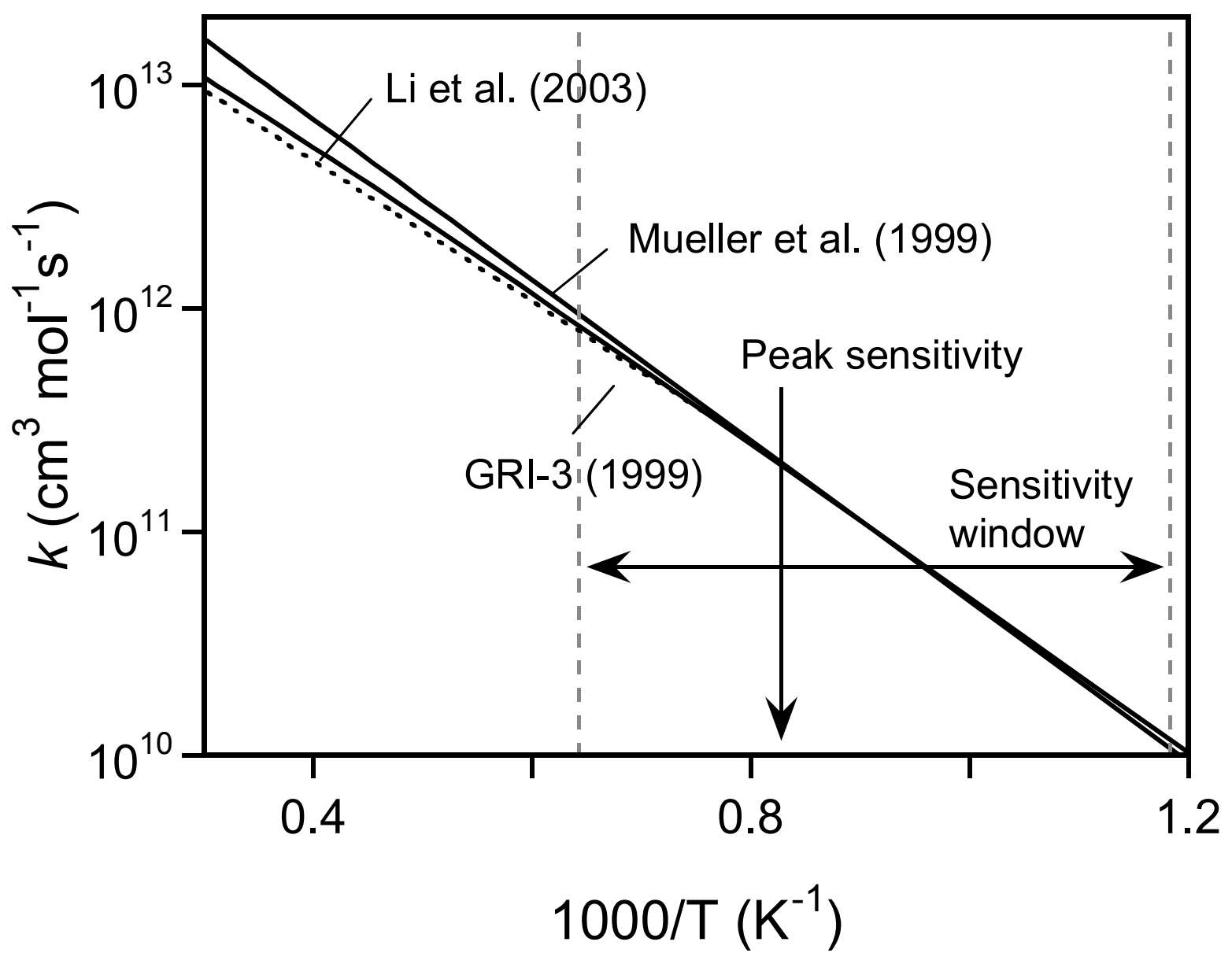

Figure 6 


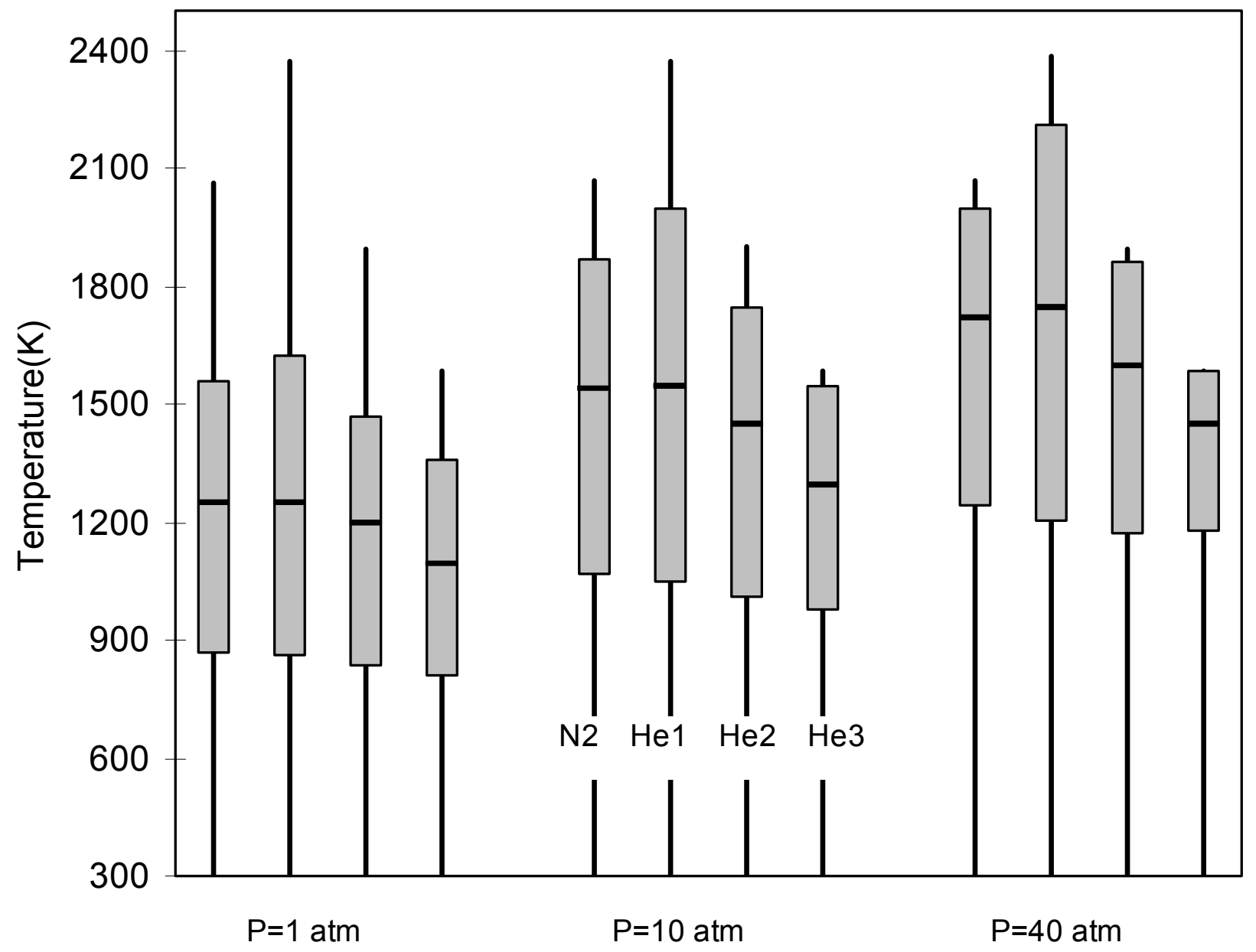

Figure 7 


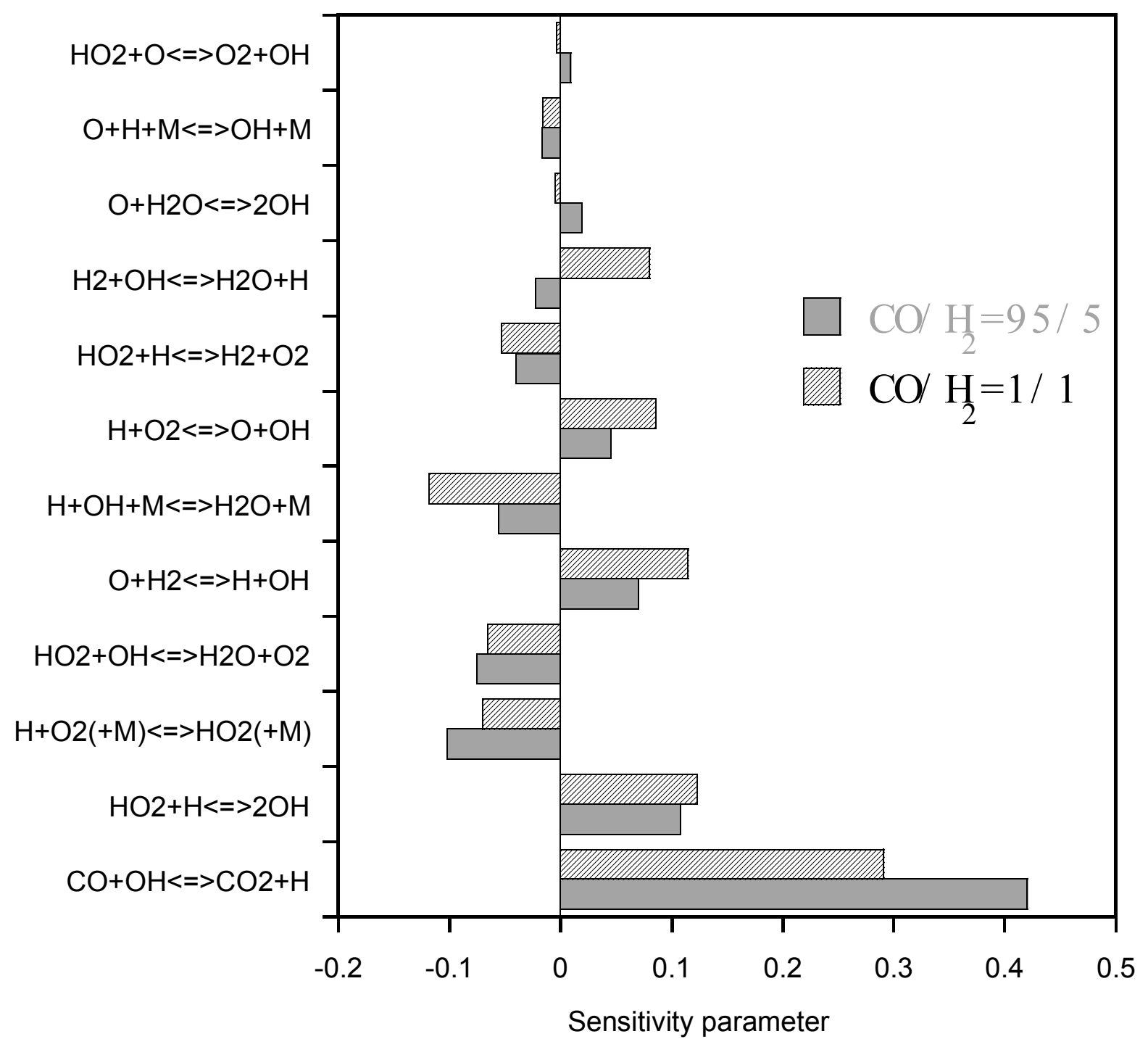

Figure 8 


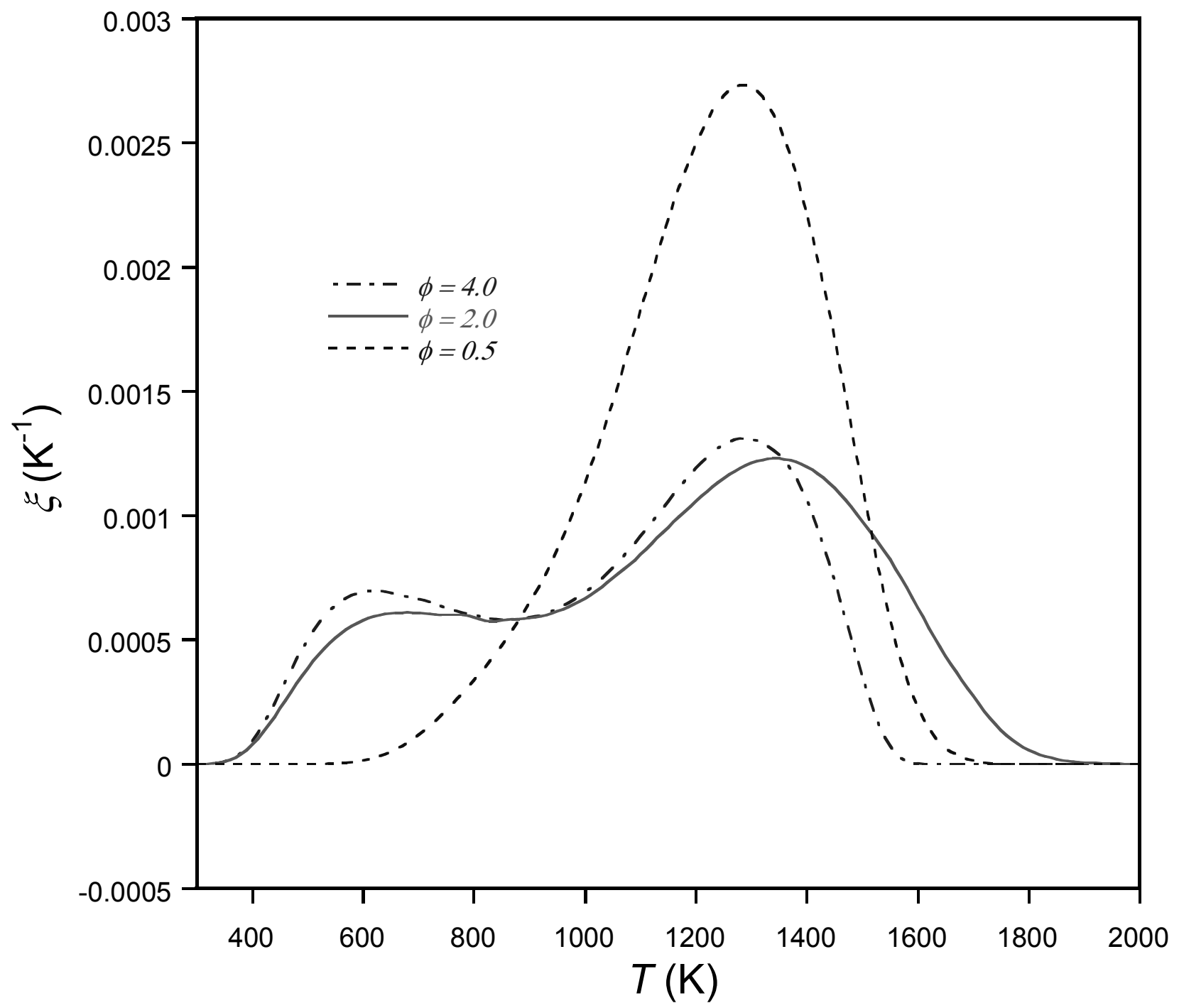

Figure 9 


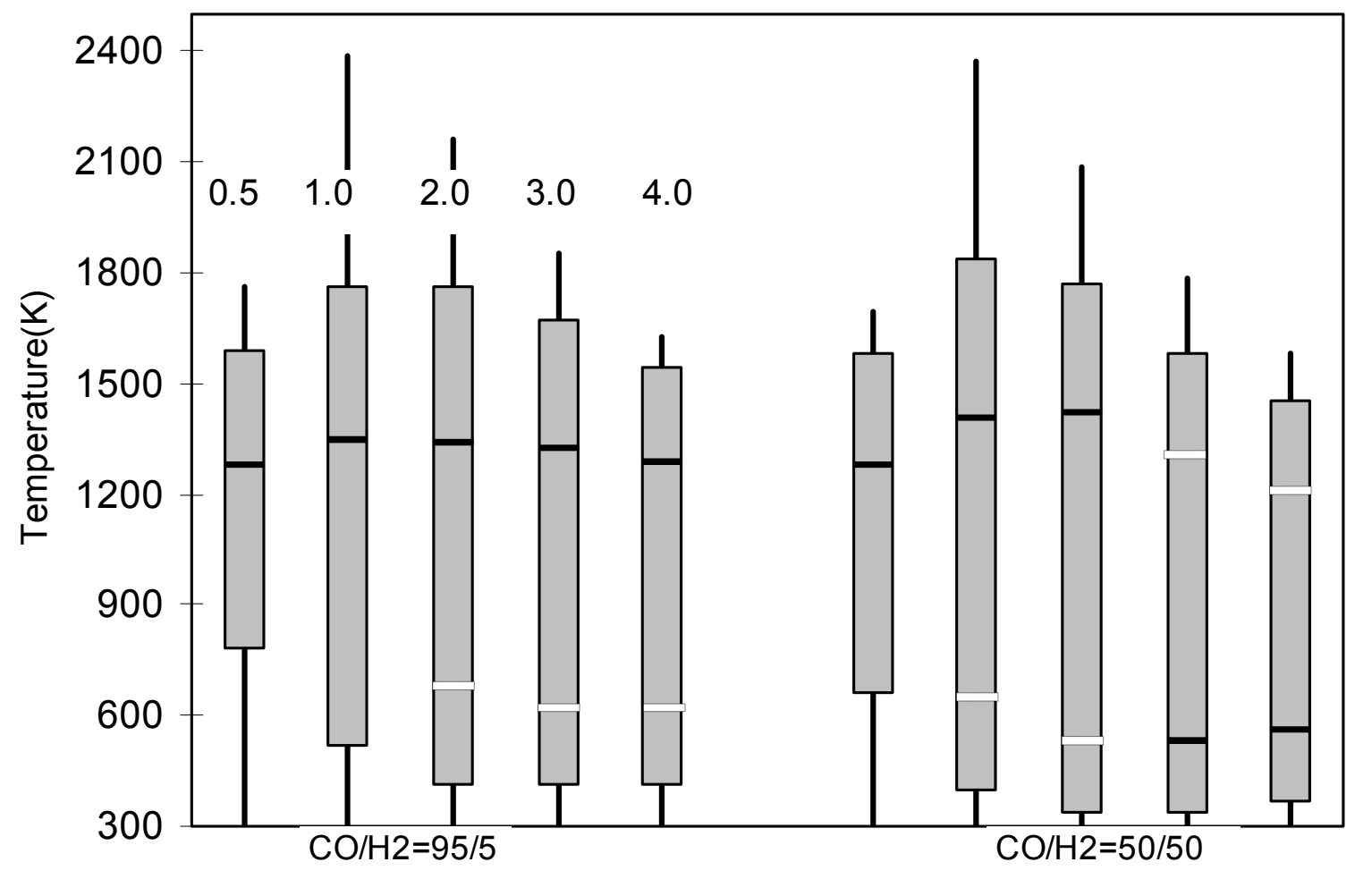

Figure 10 

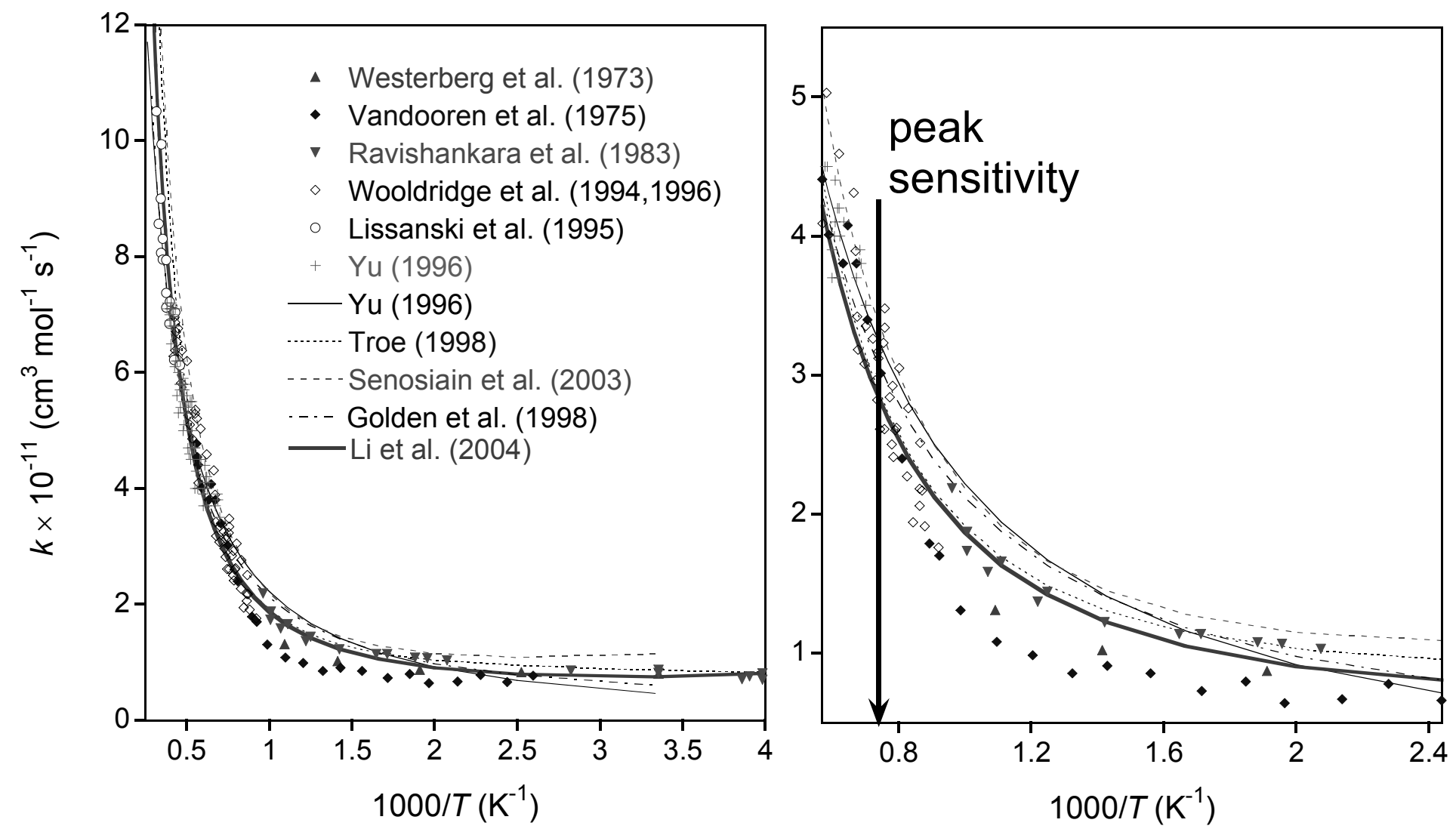

Figure 11 


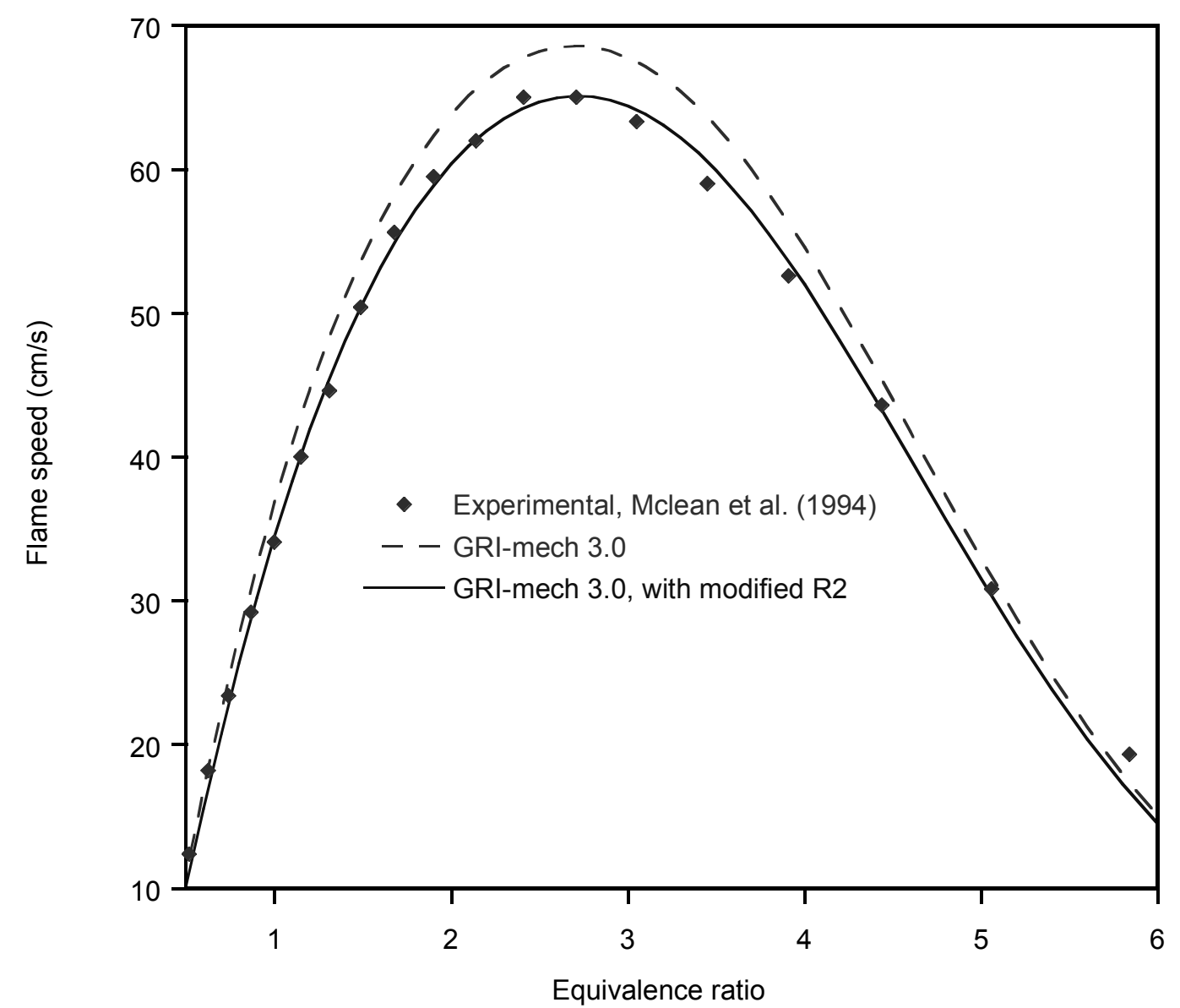

Figure 12 


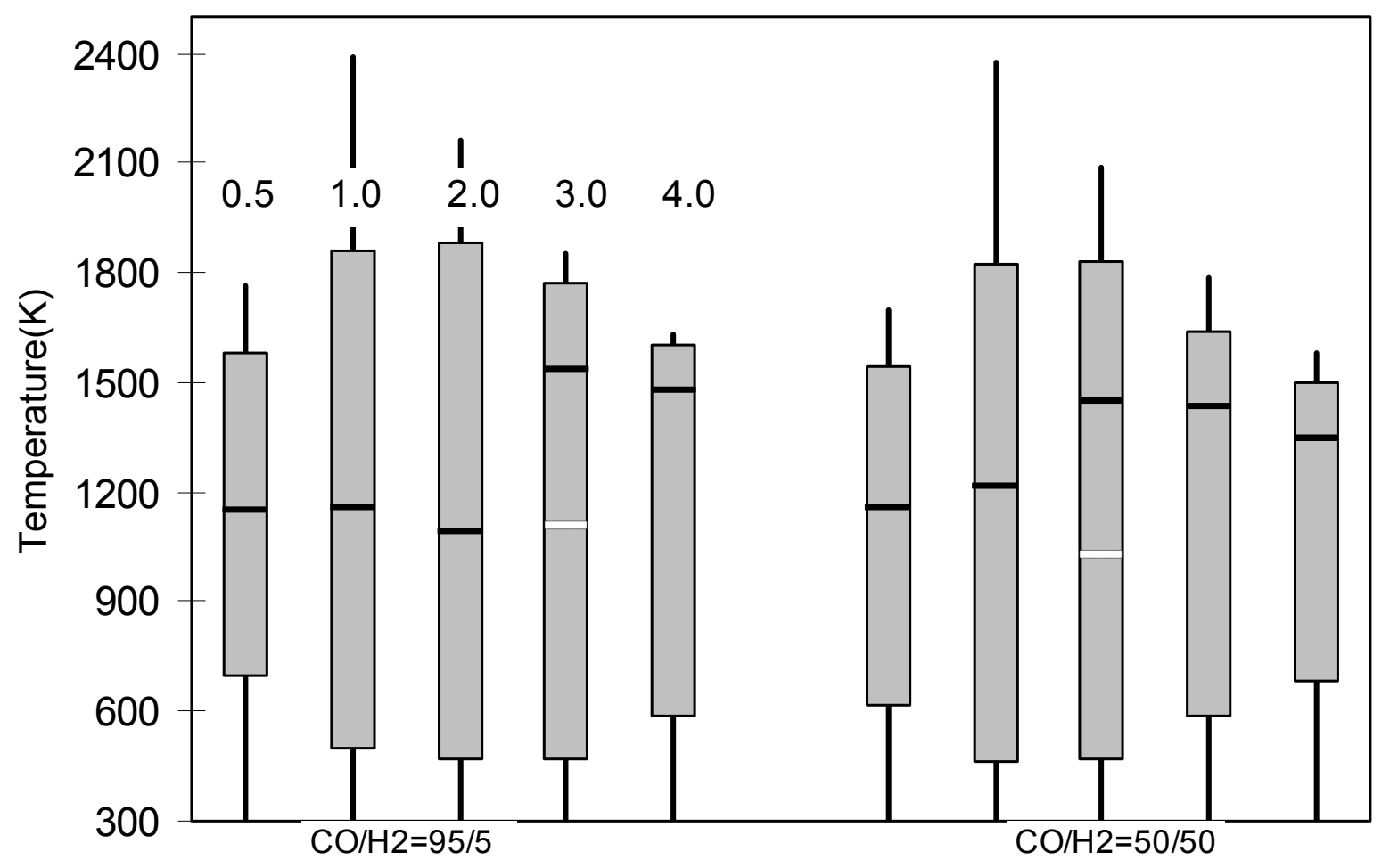

Figure 13 


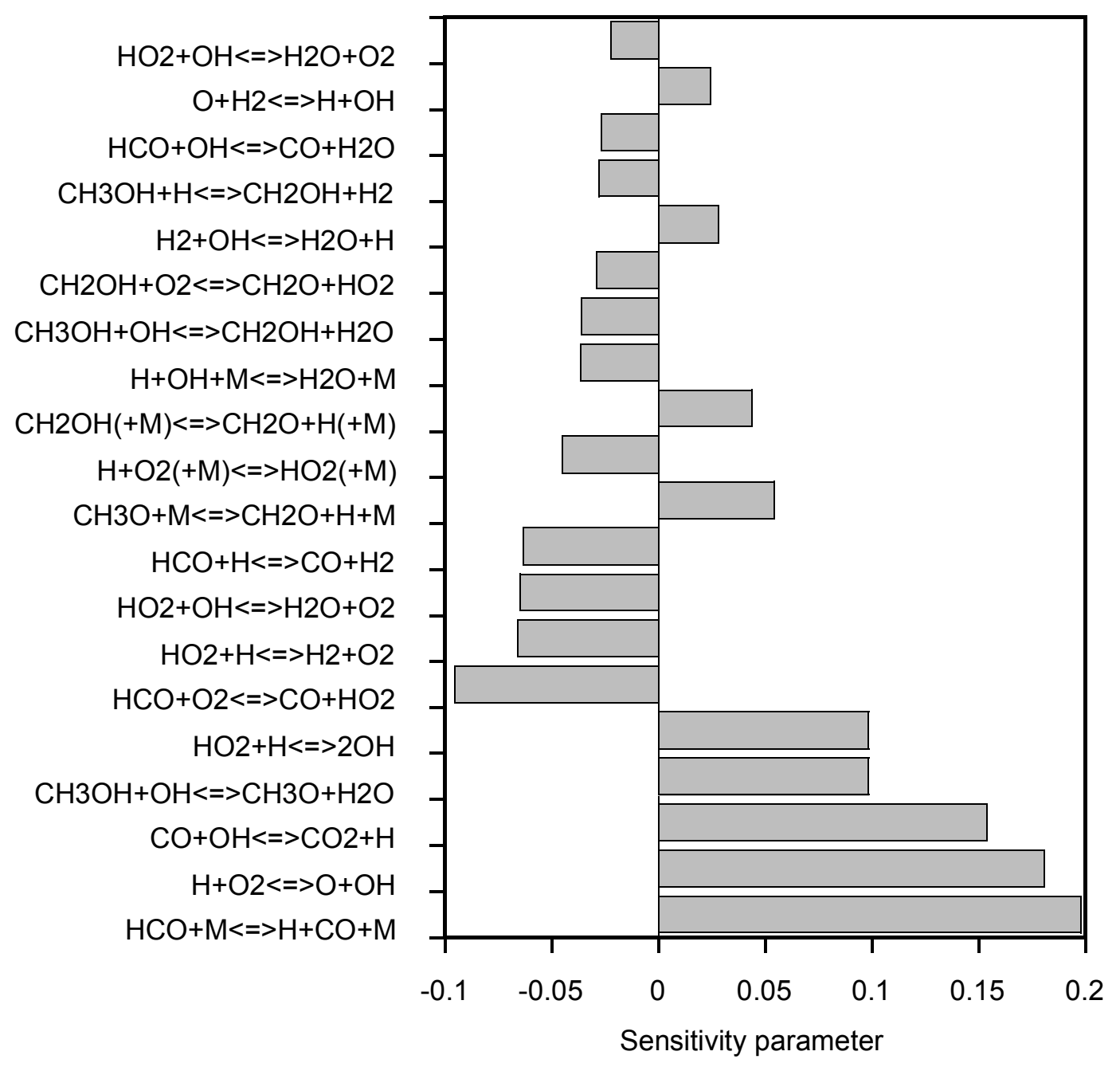

Figure 14 


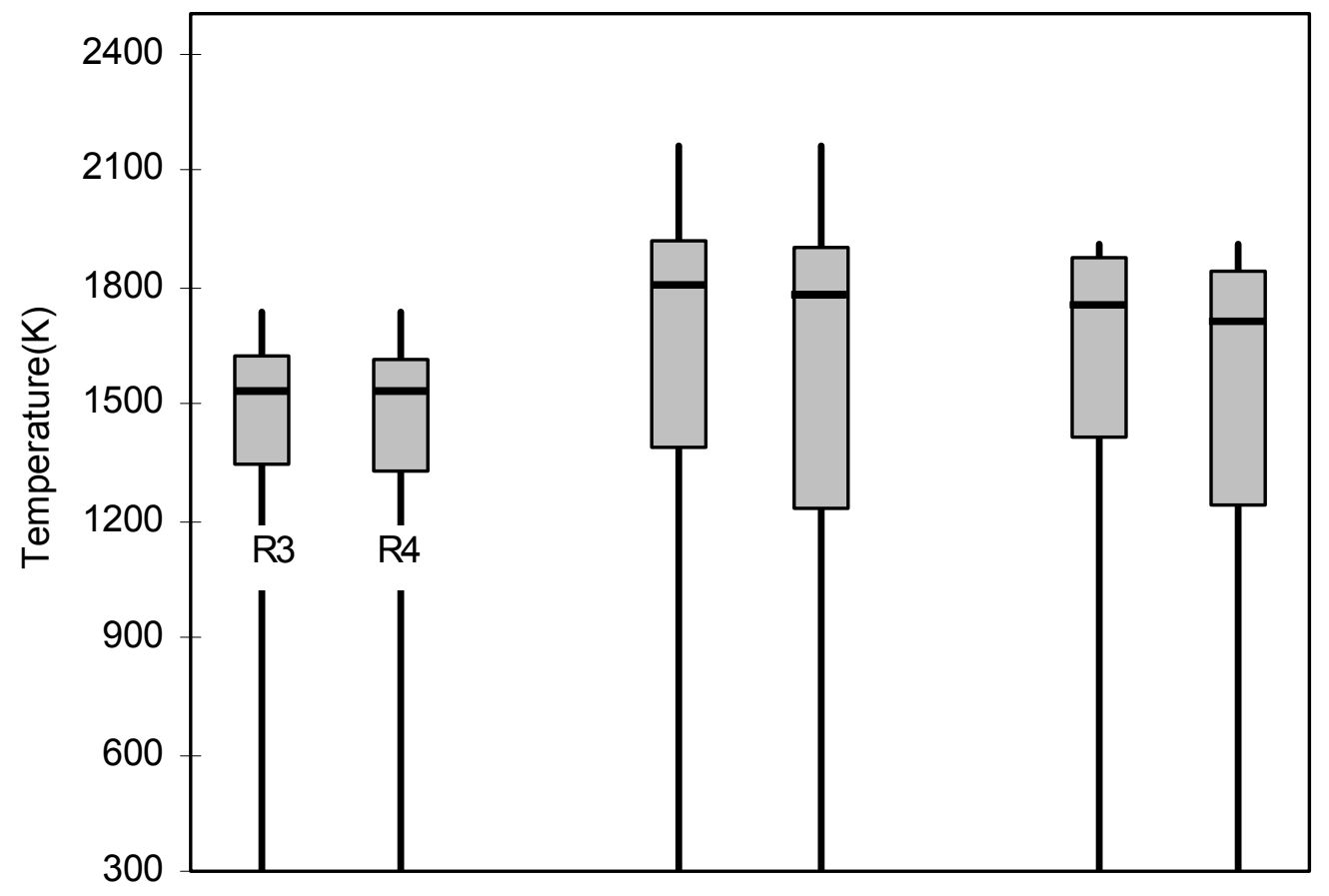

Figure 15 


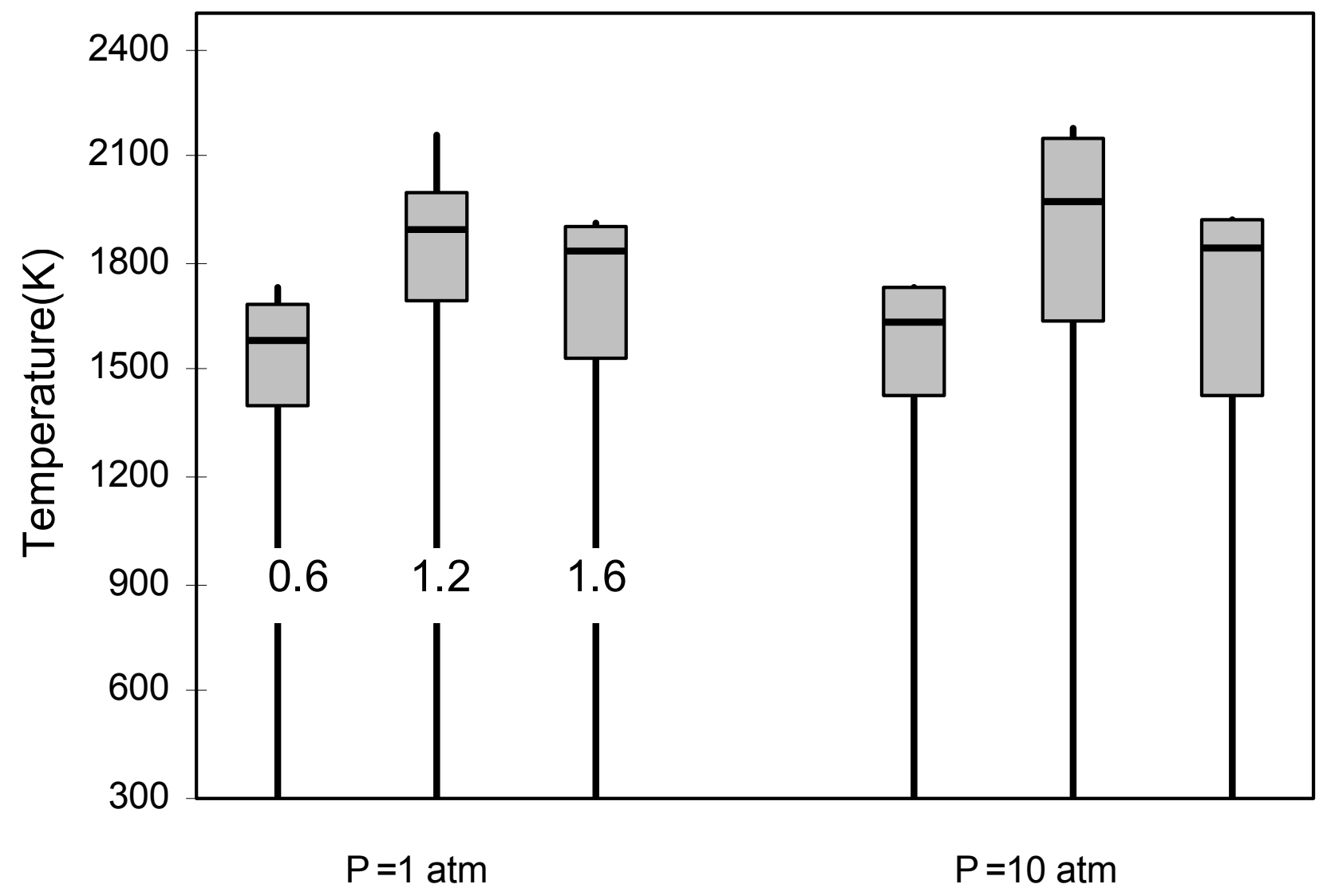

Figure 16 


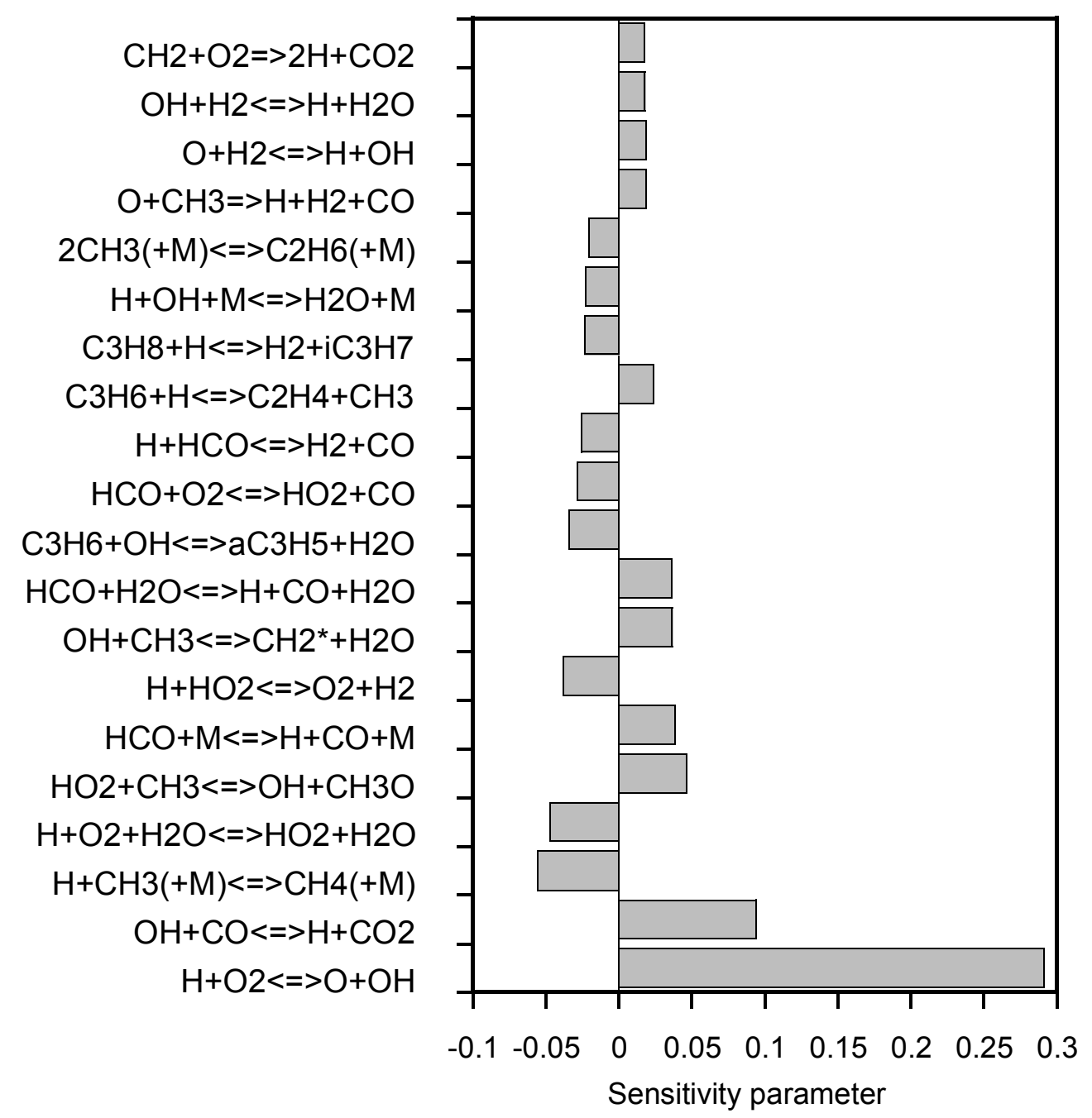

Figure 17 


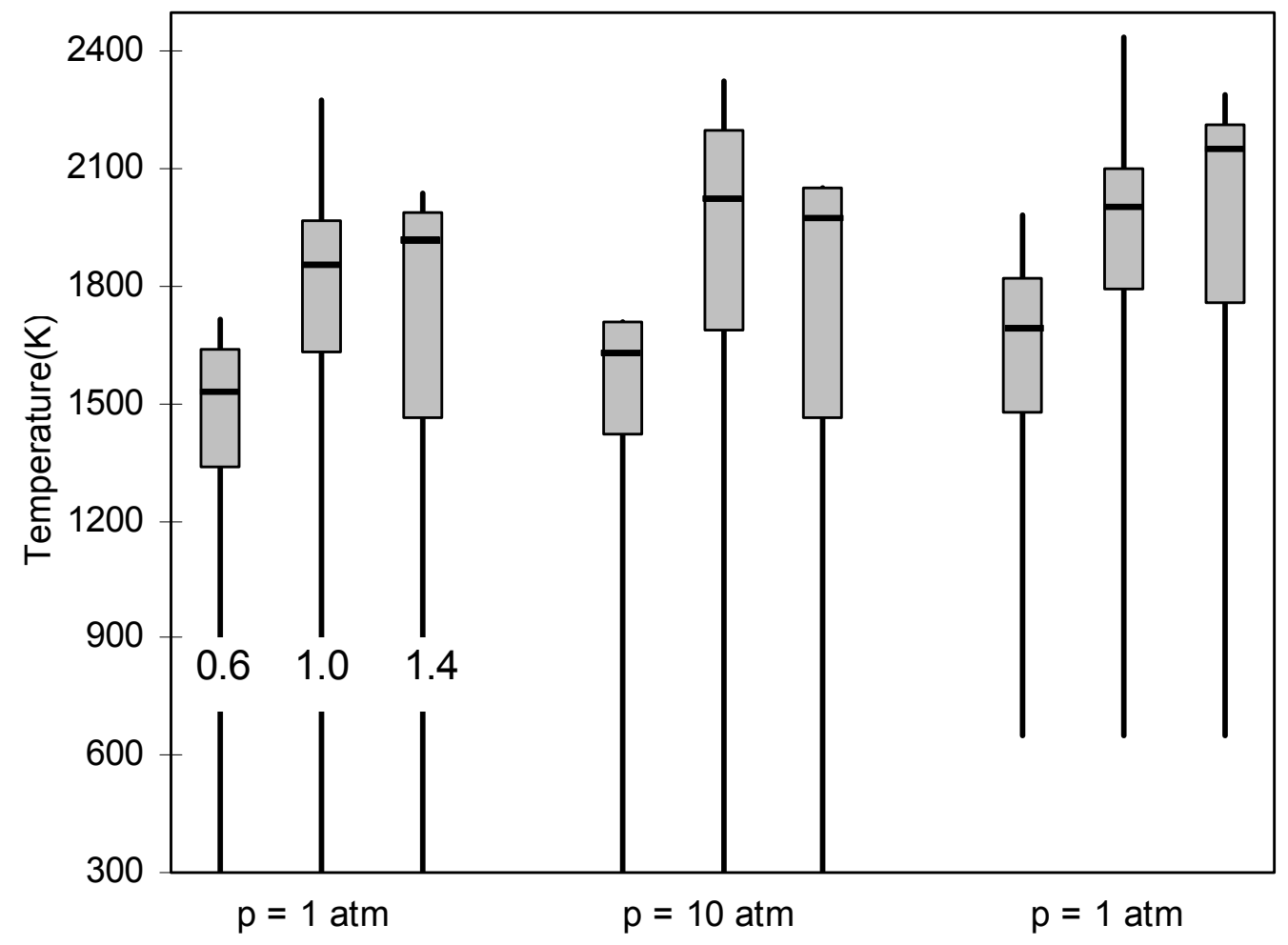

Figure 18 


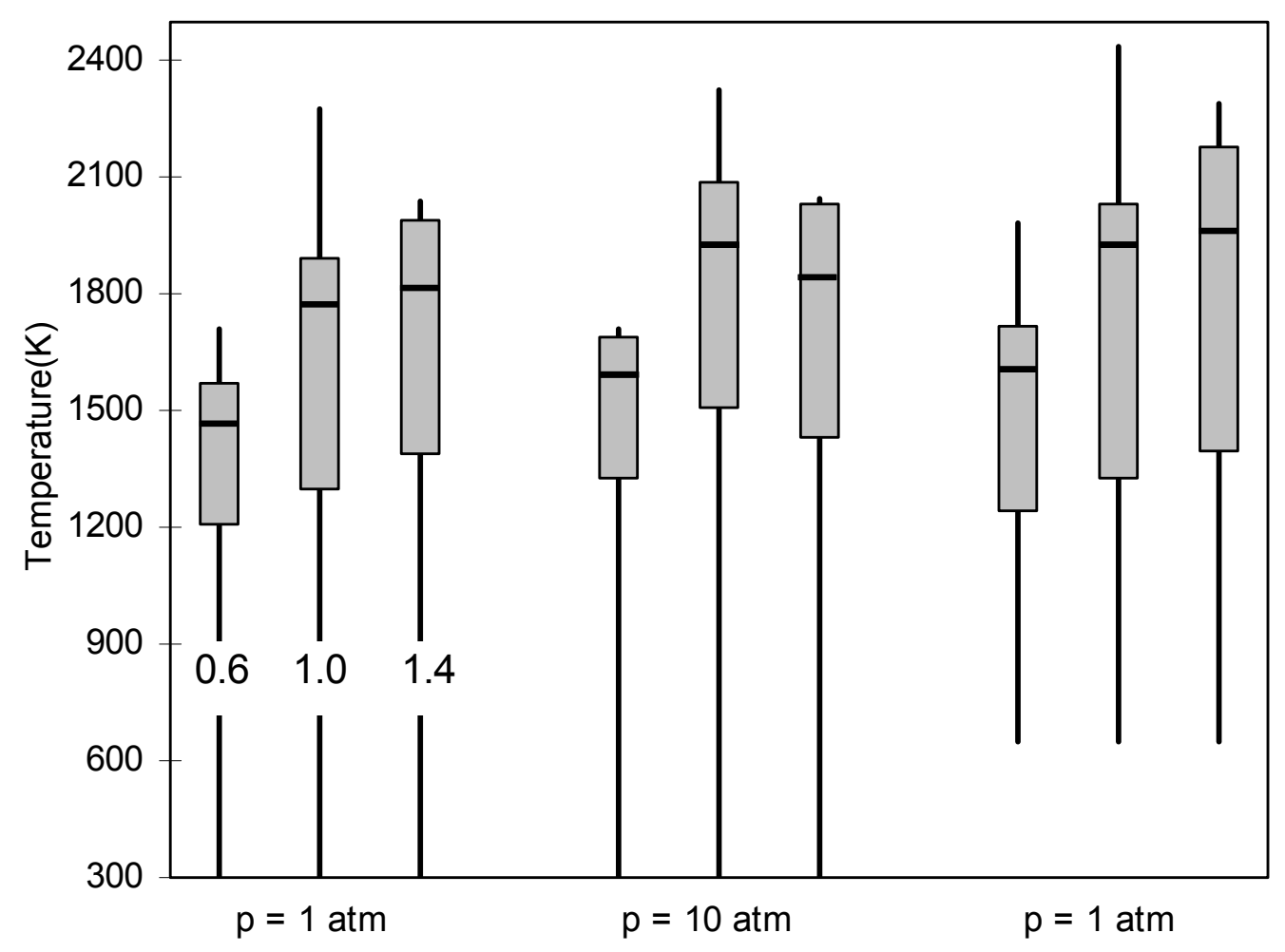

Figure 19 


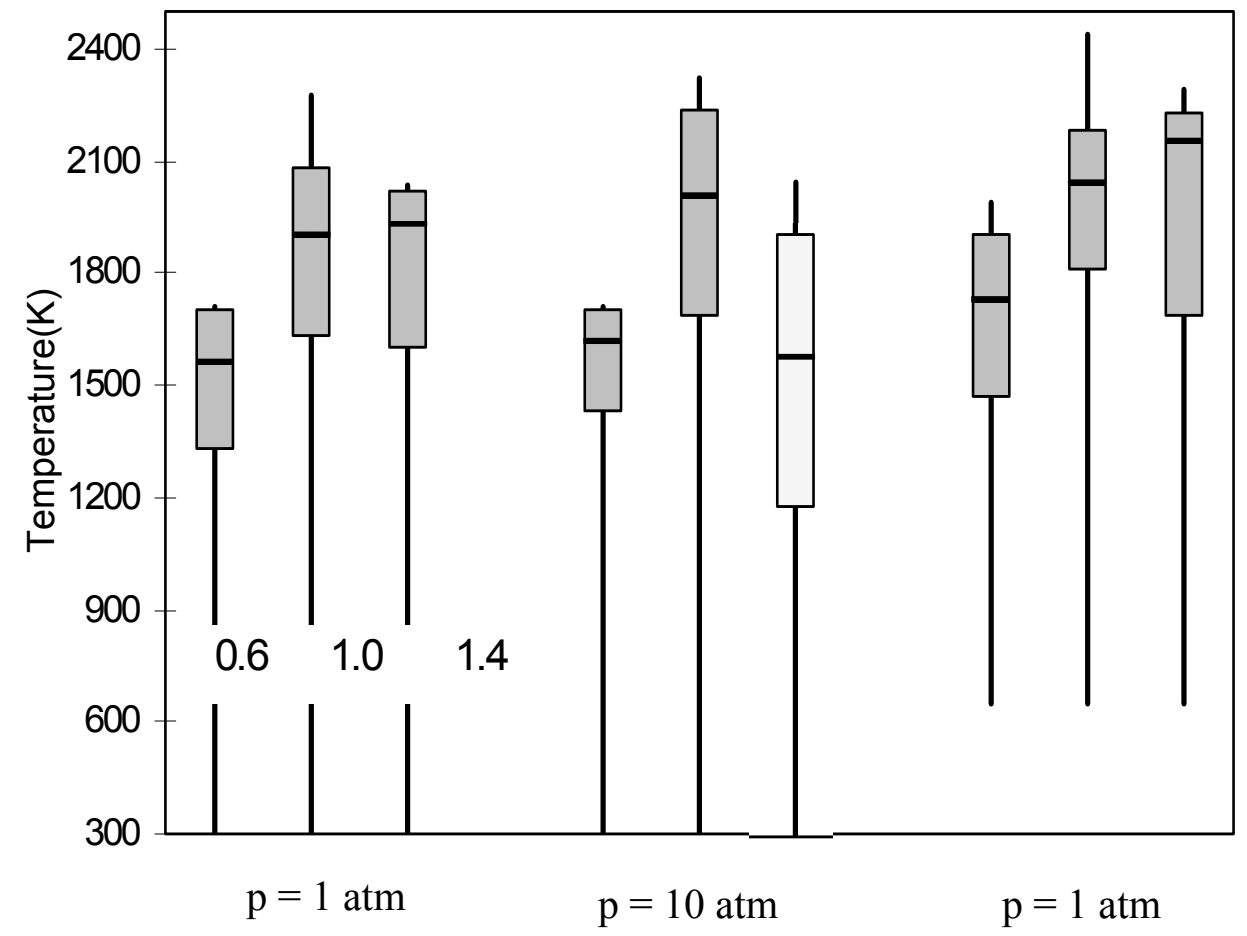

Figure 20. 


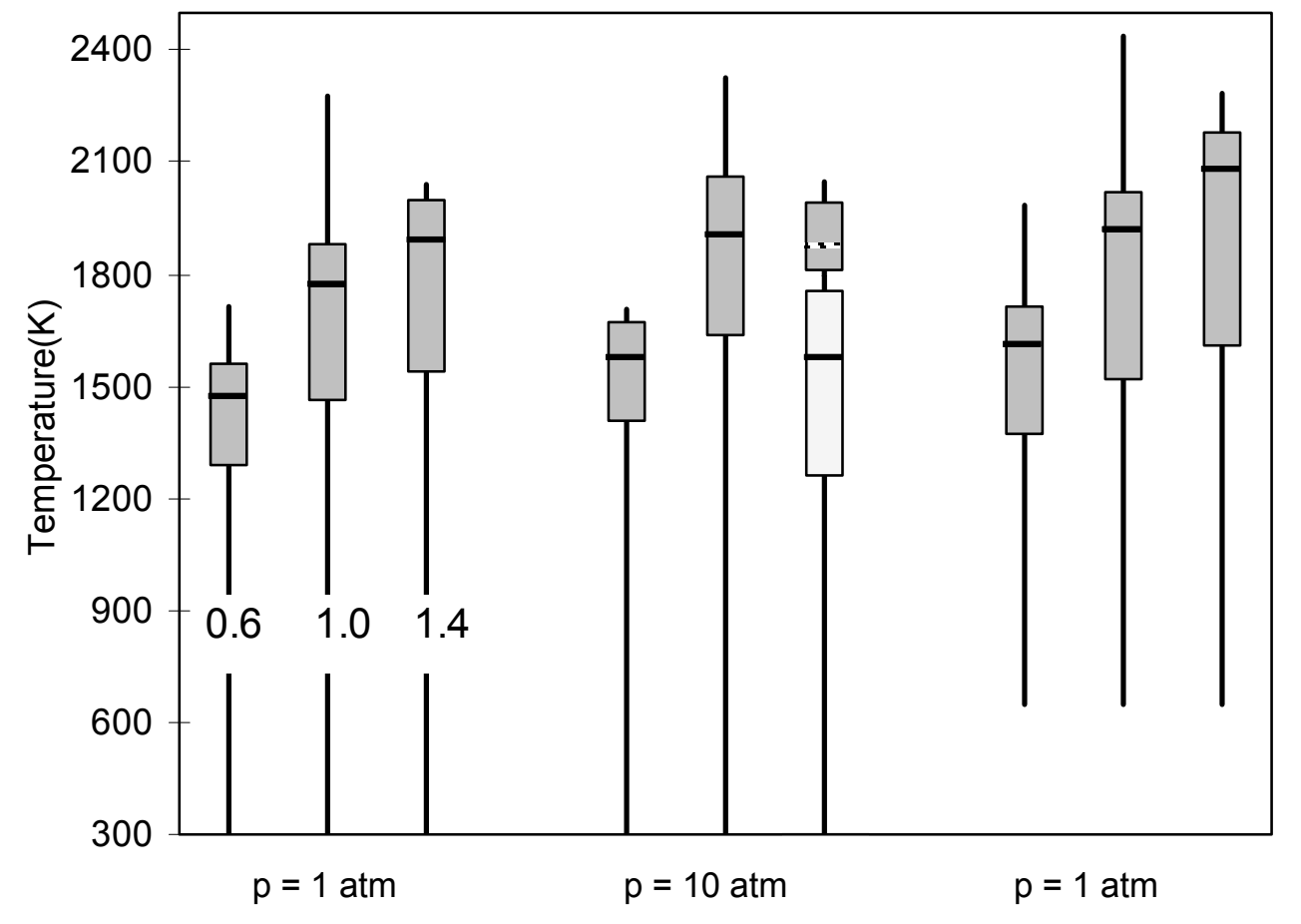

Figure 21 


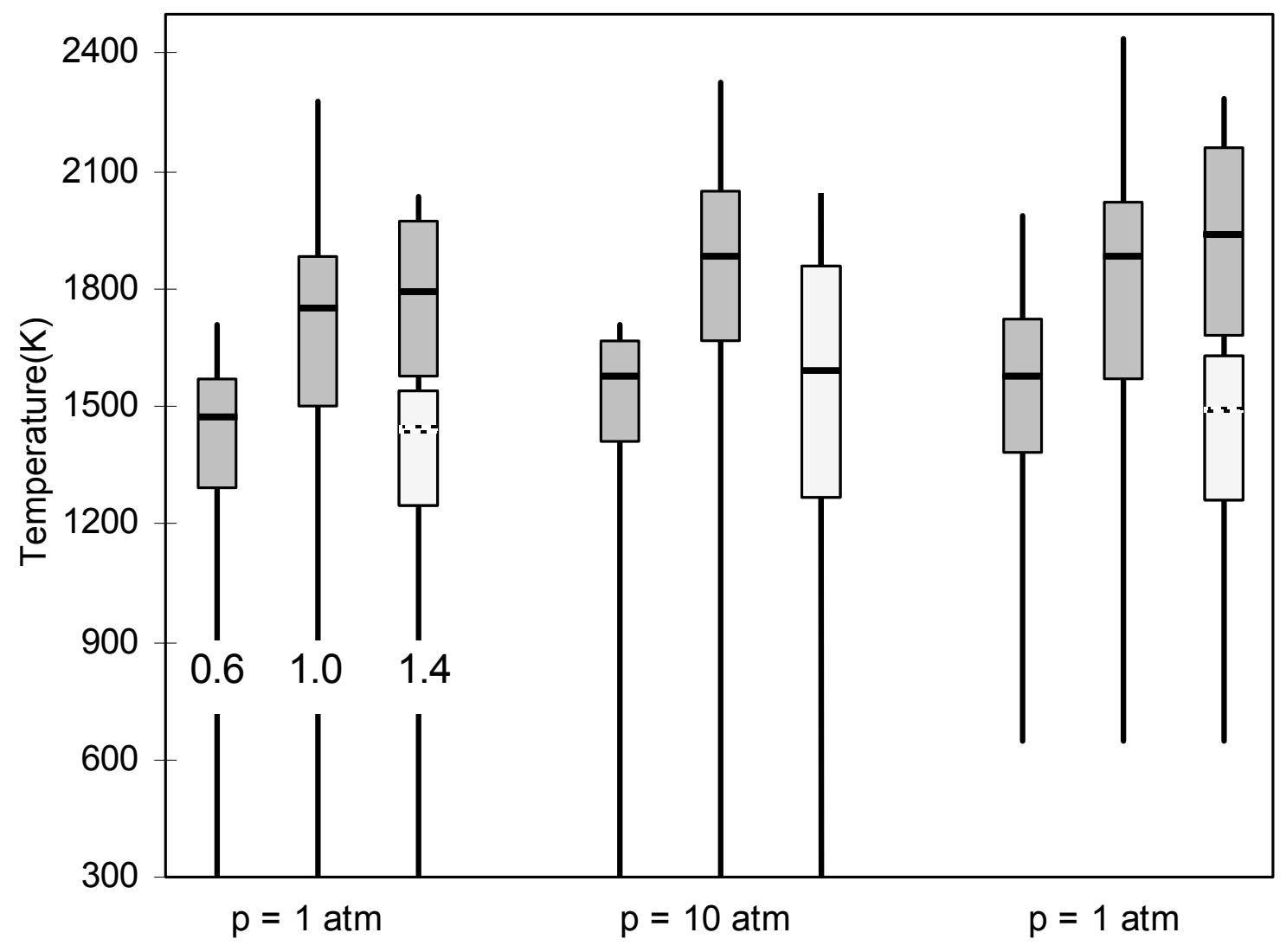

Figure 22 

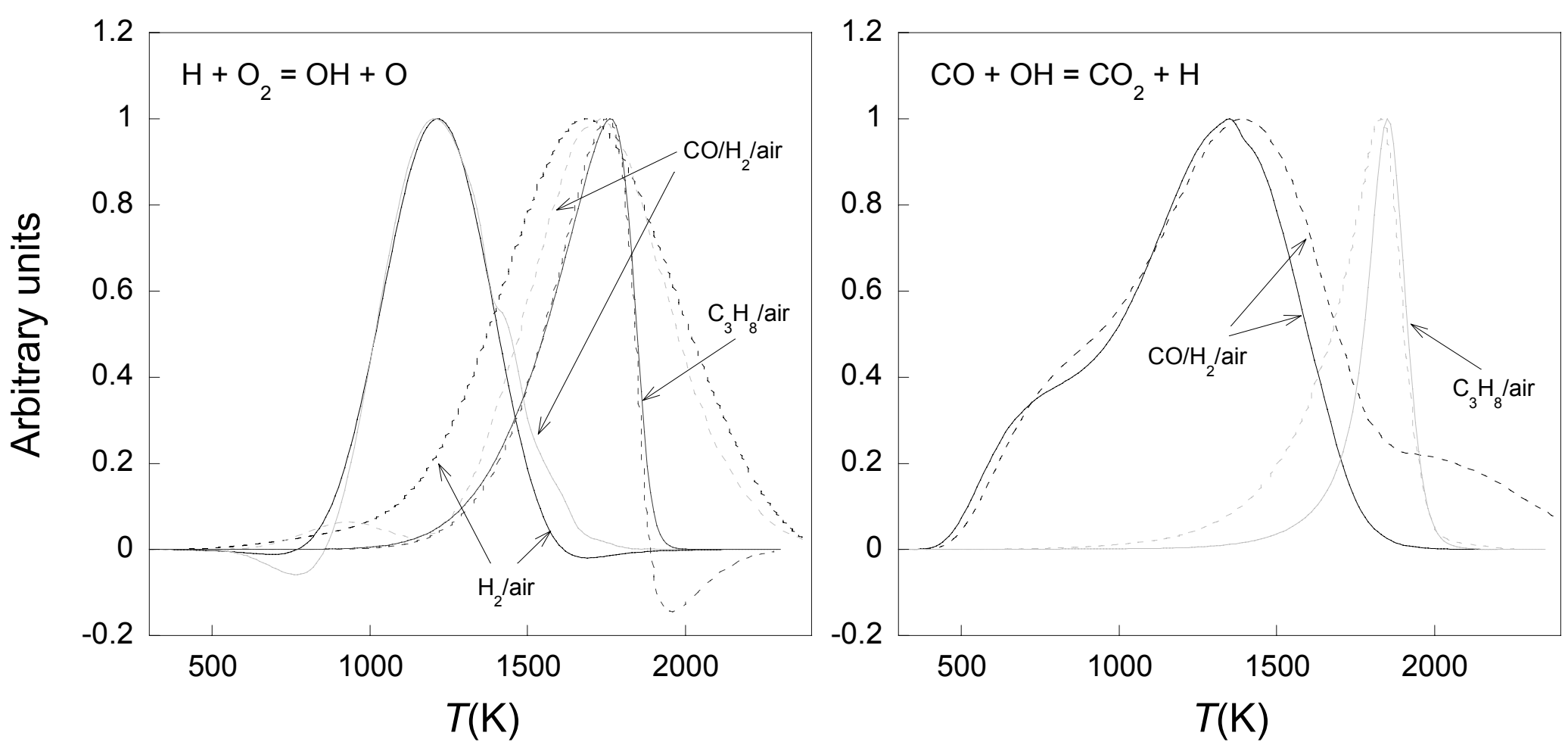

Figure 23 

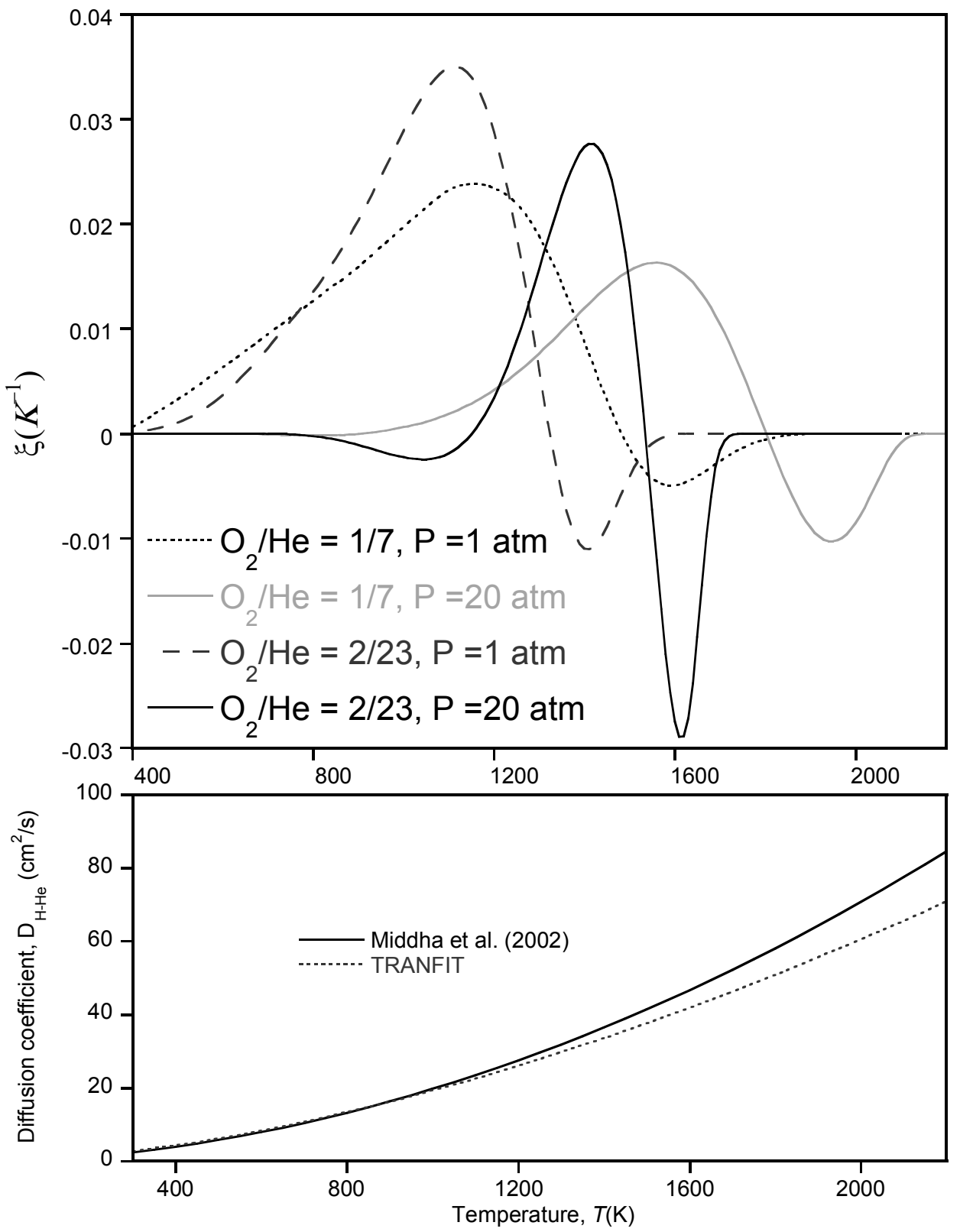

Figure 24 


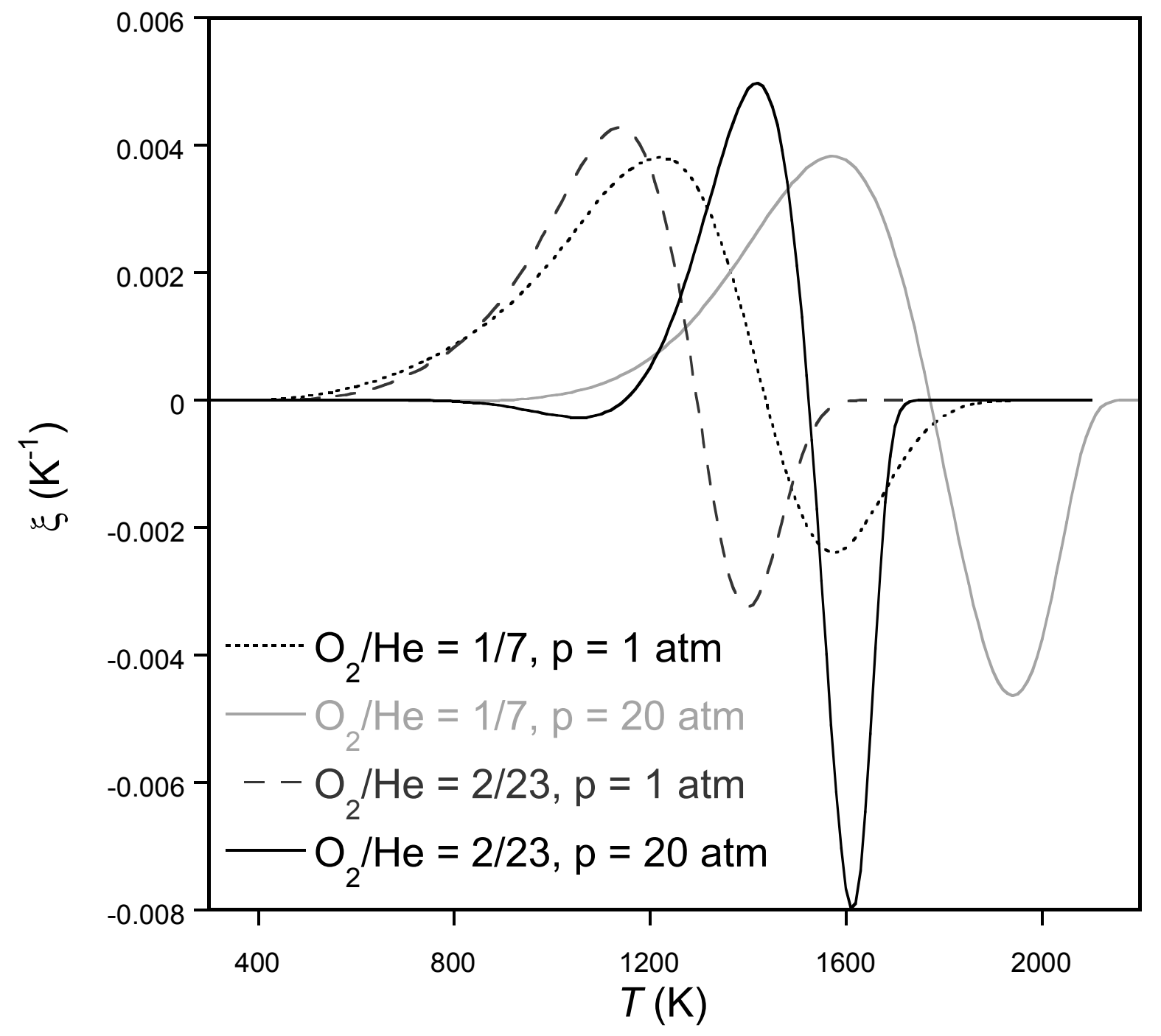

Figure 25 


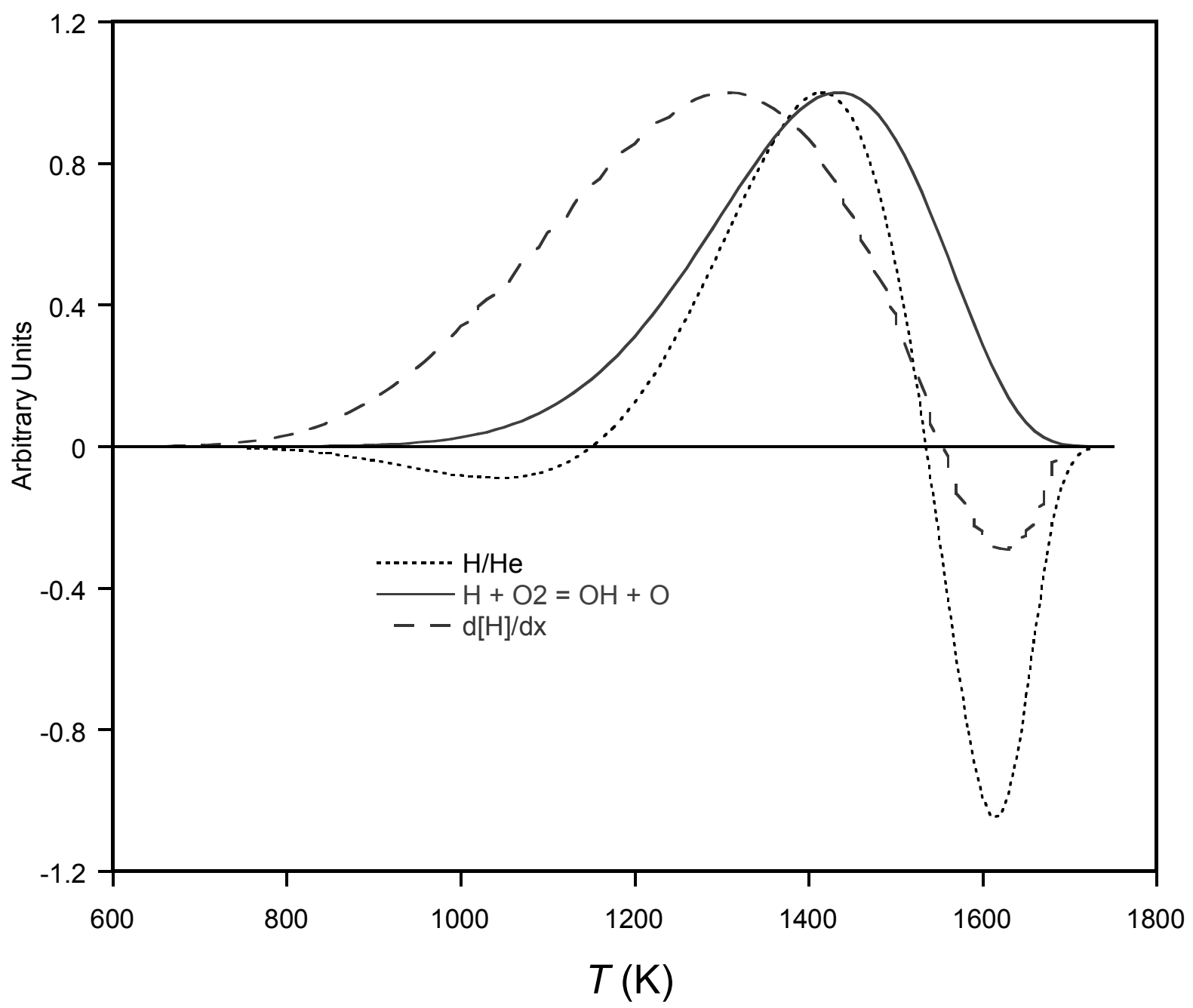

Figure 26 